$1-27-2018$

\title{
Skill Premium Divergence: the Roles of Trade, Capital and Demographics
}

\author{
Sang-Wook Stanley Cho \\ University of New South Wales \\ Julian Diaz \\ Loyola University Chicago, jdiaz17@luc.edu
}

Follow this and additional works at: https://ecommons.luc.edu/business_facpubs

Part of the Business Commons

\section{Author Manuscript}

This is a pre-publication author manuscript of the final, published article.

\section{Recommended Citation}

Cho, Sang-Wook Stanley and Diaz, Julian. Skill Premium Divergence: the Roles of Trade, Capital and Demographics. Economic Theory, 67, : 249-283, 2018. Retrieved from Loyola eCommons, School of Business: Faculty Publications and Other Works, http://dx.doi.org/10.1007/s00199-018-1098-8

This Article is brought to you for free and open access by the Faculty Publications and Other Works by Department at Loyola eCommons. It has been accepted for inclusion in School of Business: Faculty Publications and Other Works by an authorized administrator of Loyola eCommons. For more information, please contact ecommons@luc.edu.

\section{c) (i) $\Theta$}

This work is licensed under a Creative Commons Attribution-Noncommercial-No Derivative Works 3.0 License. (c) Springer, 2018. 


\title{
Skill Premium Divergence: The Roles of Trade, Capital and Demographics
}

\author{
Sang-Wook (Stanley) Cho ${ }^{1}$ \\ School of Economics, University of New South Wales, Sydney, 2052, NSW, Australia \\ Julián P. Díaz ${ }^{2, *}$ \\ Department of Economics, Quinlan School of Business, Loyola University Chicago, 820 N. Michigan \\ Avenue, Chicago, IL 60611
}

\begin{abstract}
We construct an applied general equilibrium model to account for diverging patterns of the skill premium. Our framework assesses the roles of various factors that affect the demand and supply of skilled and unskilled labor - shifts in the skill composition of the labor supply, changes in the terms of trade and the complementarity between skilled labor and equipment capital in production. We find that increases in relative skilled labor supply due to demographic changes lead to a decline in the skill premium, while equipment capital deepening raises the relative demand for skilled labor, which in turn increases the skill premium. In addition, terms of trade changes lead to the reallocation of resources towards sectors in which countries enjoy comparative advantages. Since our model incorporates multiple factors simultaneously, it can generate either rising or falling skill premium paths. When we parametrize the model to the Baltic states - countries that were similar along many dimensions at the onset of their transition from centrally-planned to market-oriented economies - our model can closely account for the diverging patterns of skill premia observed in the Baltics between 1995 and 2008.
\end{abstract}

JEL classification: E16, E25, J24, J31

Keywords: skill premium, international trade, capital-skill complementarity, demographic change, Baltic states

\footnotetext{
${ }^{*}$ We wish to thank the Co-Editor and two anonymous referees for their thorough revisions and helpful suggestions that significantly improved this article. We also thank seminar participants at the Sydney Macro Reading Group Workshop, University of Tartu, Stockholm School of Economics in Riga, the Bank of Estonia and the Central Bank of Chile for their comments.

${ }^{1}$ Email: s.cho@unsw.edu.au; Tel.: +61 (2) 9385-3287.

${ }^{2}$ Email: jdiaz17@luc.edu; Tel.: +1 (312) 915-7045.
} 


\section{Introduction}

Because of their implications for income inequality, the patterns of the skill premiumdefined as the wage of skilled labor relative to that of unskilled labor-have received a considerable amount of attention in the Economics literature in recent years. Indeed, a considerable number of articles have been written on the topic, documenting and accounting for skill premium trends across developed and developing economies.

Although no unanimous consensus has yet been reached on which factors definitively drive the movements of the skill premium, a few hypotheses have emerged as prime candidates: technological change that favors skilled workers because they are complementary to capital, as originally formalized by Griliches (1969), and later examined quantitatively by Krusell et al. (2000) and Polgreen and Silos (2008); the expansion of trade that encourages production in sectors that use a particular type of labor intensively (see Kurokawa 2012 for a recent survey of this strand of the literature); and the abundance of skilled labor relative to unskilled labor, as analyzed in Katz and Murphy (1992) and Goldin and Katz (2008). However, a common shortcoming of a vast array of studies dealing with the subject is that they focus on the effects of one single factor on the skill premium, thus neglecting the potential interactions of the other explanations.

To address this issue, we propose a static general equilibrium model that can embody all three factors simultaneously. The model features a multi-sector small open economy that trades with the rest of the world, with production sectors that utilize skilled and unskilled labor with different skill intensities. Thus, terms of trade shocks that, for example, promote increased production in a sector with a particular level of skill intensity will have further effects on the skill premium. Moreover, the domestic production technology displays complementarity between equipment capital and skilled labor, so episodes of rapid capital expansion will be biased towards benefiting skilled workers and increasing their wages. Finally, our model also includes labor supply decisions for both types of workers, so increases or decreases in the different types of labor supply (resulting from demographic changes) that alter their relative abundances will in turn be reflected in the skill premium.11

Our model is simple and tractable enough that it allows us to discern the mechanisms that yield the outcomes generated by exogenous changes in factors that affect both labor demand and labor supply. We can also conduct a decomposition analysis to quantify the individual roles played by capital, trade and demographic factors. In fact, we show that

\footnotetext{
${ }^{1}$ Certainly, a dynamic model would be the ideal framework to analyze the effects of physical and capital accumulation on the skill premium. However, as we discuss later, we also want to calibrate our model to conduct numerical simulations to assess the quantitative predictions of our theoretical model. The lack of comparable micro data constrains our analysis to a static one.
} 
using the first order conditions derived from the optimizing behavior of the agents in our model, we can analytically decompose the growth of the skill premium into one equation for each country, whose solution depends on the three terms. The first one implies that the relative growth rates of equipment capital and skilled labor are positively correlated with the skill premium; the second one implies that the relative growth rates of skilled labor and unskilled labor are negatively correlated with the skill premium; finally, the third term embodies the Heckscher-Ohlin ( $\mathrm{H}-\mathrm{O})$ mechanism, where reductions in trade costs lead to factor reallocation towards the sectors where the country enjoys comparative advantages, and thus raise the relative return to the factor that is more intensively used in those sectors. In that sense, our model allows us to explore labor demand and labor supply implications on relative wages and therefore the skill premium.

Since our model incorporates multiple factors at the same time, their overall effect could theoretically lead to skill premium increases or decreases. To assess whether our model generates predictions that are in line with actual data observations, we apply it to account for the patterns of the skill premium in the Baltic states: Estonia, Latvia and Lithuania. These countries represent an interesting application for at least two reasons. First, as these nations transitioned from centrally-planned to free-market systems, they aggressively opened their economies to the rest of the world, accumulated massive amounts of capital stock, and experienced significant changes in the skill composition of their labor forces. So all three factors that we include in our model were actively operating in their economies. Second, despite many similarities in their economies at the onset of their transition, their skill premia followed very different patterns. Indeed, between 1995 and 2008, the skill premium in Latvia increased by nearly 16\%, while in Estonia and Lithuania it declined by $20 \%$ and $13 \%$, respectively.

When we calibrate our model to match the Baltic data and conduct comparative statics experiments that replicate the paths of capital stock accumulation, terms of trade and changes in the relative skill composition of the labor force that the Baltic states experienced, our model predicts decreases in the Estonian and Lithuanian skill premium of $22 \%$ and $35 \%$, respectively, and an increase in the Latvian skill premium of $10 \%$. Therefore, our model produces skill premium movements that are consistent with those observed in the Baltics, both qualitatively and quantitatively.

Our results indicate that the divergence of skill premium in the Baltics is the result of forces that affect skill premium in opposite directions. More specifically, we find that the changes in demographics - through increases in the relative skill supply-lead to a decline in the skill premium, while equipment capital deepening raises the relative demand for skilled labor and thus increases the skill premium. In addition, favorable terms of trade lead to the 
reallocation of factors towards sectors in which the transition economies have comparative advantages. As the Baltic states have a comparative advantage in unskilled-intensive sectors, the cross-sector reallocation of resources lowers the skill premium. All in all, our model suggests that in Estonia and Lithuania, the forces that lower skill premium dominated the force that raises it, whereas in Latvia the opposite effect took place.

Thus, our contribution to the literature consists in a unified framework that collapses into a tractable analytical solution that simultaneously incorporates both labor demand and supply factors to account for skill premium changes. In a recent article, Parro (2013) constructs a static quantitative model of trade and finds that when the capital-skill complementarity channel is included, reductions in the cost of capital goods due to technological progress and in trade costs lead to increases in the skill premium for a sample of developed and developing countries. His model, however, generates only skill premium increases, even for countries that experienced declines in the skilled relative wage. Our model, in contrast, yields increases and decreases in the skill premium because it includes labor supply effects that sometimes can outweigh the labor demand effects that are biased towards skilled workers. Ripoll (2005), on the other hand, constructs a dynamic general equilibrium model that features trade shocks and skill accumulation choices - though not capital-skill complementarity - to analyze the patterns of the skill premium in developing economies. Her model is able to generate skill premium series that exhibit increasing or decreasing paths, but those trends are due to differences in initial conditions across countries in terms of human and physical capital stocks. Our model, instead, produces diverging skill premium paths for economies that were initially quite similar in those dimensions. Moreover, our model fits the Baltic data fairly well, while Ripoll's study is purely theoretical. Finally, our model highlights the potential interactions between the labor demand and labor supply factors. Indeed, we show that the outcome on the skill premium when both types of factors are taken into account simultaneously can be quantitatively different from just the sum of the single-factor results, which was not explored in other studies, including Krusell et al. (2000).

The rest of the paper is organized as follows. Section 2 describes the model and the analytical derivation of skill premium implied by it. Section 3 motivates the application of our model to the Baltic states by documenting the patterns of the skill premium in those countries, as well as providing a brief overview of the their economies. Section 4 details the calibration of the model, and Section 5 describes the numerical experiments we conduct and the results we obtain. In Section 6 we check the robustness of our results by running a series of sensitivity analyses, including one where we assess the predictions generated by our model for shorter horizons. We conclude in Section 7. 


\section{Model}

We build a static general equilibrium model that incorporates endogenous labor-leisure decisions, international trade, and complementarity between skilled labor and equipment capital in production. The model is composed of two countries: a small open economywhich cannot affect foreign prices and takes them as exogenous - and the rest of the world. The small open economy is populated by several agents: two representative households (differentiated by their skill levels), producers, and a government. Since our focus is on the small open economy, the rest of the world is modeled in simpler detail. The preferences and technologies of the agents in our model, as well as the way agents interact with each other, are described below.

\subsection{Production}

Two commodities are produced in the small open economy: goods $(G)$ and services $(S)$. We denote the set of commodities by $I$. Each commodity $i \in I$ is made up of a domestic component $y_{d, i}$ and a foreign component $y_{f, i}$ which is imported from the same sector in the

rest of the world. The domestic and imported components are combined using an Armington aggregator of the form:

$$
y_{i}=\phi_{i}\left[\delta_{i} y_{d, i}^{\rho_{m, i}}+\left(1-\delta_{i}\right) y_{f, i}^{\rho_{m, i}}\right]^{\frac{1}{\rho_{m, i}}}
$$

where $\rho_{m, i}$ is the parameter that governs the elasticity of substitution between domestic and imported components in sector $i, \delta_{i}$ is the parameter which governs the share of imports in the production of commodity $i$, and $\phi_{i}$ is the parameter that reflects the level of productivity in the final goods production in sector $i$. Imports of commodity $i$ are purchased at the international price $\bar{p}_{f, i}$, which the small economy takes as given, and are subject to an advalorem tariff rate $\tau_{f, i}$, while purchases of the domestic component are subject to a production tax rate $t_{i}$.

\subsection{Domestic Component Producer}

The domestic component $y_{d, i}$ is produced using intermediate inputs from all sectors $x_{j, i}$ in fixed proportions, capital structures and equipment $k_{z, i}$ and $k_{e, i}$, and skilled and unskilled labor $\ell_{s, i}$ and $\ell_{u, i}$ :

$$
y_{d, i}=\min \left\{\frac{x_{1, i}}{a_{1, i}}, \ldots, \frac{x_{n, i}}{a_{n, i}}, \beta_{i} k_{z, i}^{\alpha_{i}}\left[\lambda_{i}\left[\mu_{i} k_{e, i}^{\rho}+\left(1-\mu_{i}\right) \ell_{s, i}^{\rho}\right]^{\frac{\sigma}{\rho}}+\left(1-\lambda_{i}\right) \ell_{u, i}^{\sigma}\right]^{\frac{1-\alpha_{i}}{\sigma}}\right\}
$$

where $a_{j, i}$ is the unit requirement of intermediate input $j$ in the production of commodity $i ; \alpha_{i}, \mu_{i}$ and $\lambda_{i}$ are the share parameters of inputs in value added; $\beta_{i}$ is the parameter that reflects the level of productivity in the domestic production in sector $i ; 1 /(1-\rho)$ is the 
elasticity of substitution between equipment and skilled labor; and $1 /(1-\sigma)$ is the elasticity of substitution between unskilled labor and equipment or skilled labor. We follow Krusell et al. (2000) in assuming that value added is produced as a Cobb-Douglas combination of structures and a CES combination of equipment and the two types of labor.

\subsection{Investment Good}

We include an investment good in order to account for the savings observed in the data. In a dynamic model, agents save in order to enjoy future consumption. In a static model like the one we use, agents derive utility from consuming the investment good, just as they derive utility from the consumption goods. The investment good $y_{i n v}$ is produced by a firm that combines the final goods as intermediate inputs using a fixed proportions technology, as shown:

$$
y_{i n v}=\min \left\{\frac{x_{1, i n v}}{a_{1, i n v}}, \ldots, \frac{x_{i, i n v}}{a_{i, i n v}}, \ldots, \frac{x_{n, i n v}}{a_{n, i n v}}\right\}
$$

\subsection{Households}

The small open economy is populated by two representative households: skilled $(s)$ and unskilled $(u)$. We denote the set of households by $H$. Each type of household $j \in H$ chooses consumption, savings and leisure to maximize its utility:

$$
\left[\zeta_{j}\left(\sum_{i \in I} \theta_{i}^{j} c_{i, j}^{\eta}+\theta_{i n v}^{j}\left(c_{i n v, j}+c_{b, j}\right)^{\eta}\right)^{\frac{\psi}{\eta}}+\left(1-\zeta_{j}\right)\left(\bar{L}_{j}-\ell_{j}\right)^{\psi}\right]^{\frac{1}{\psi}}
$$

subject to the budget constraint

$$
\sum_{i \in I} p_{i} c_{i, j}+p_{i n v}\left(c_{i n v, j}+c_{b, j}\right)=\left(1-t_{d}^{j}\right)\left(w_{j} \ell_{j}+r_{e} \bar{k}_{e, j}+r_{z} \bar{k}_{z, j}\right)
$$

where $c_{i, j}$ is consumption of commodity $i$ by household $j$ and $p_{i}$ its price; $\bar{L}_{j}$ is the total number of available hours and $\ell_{j}$ is hours worked; $1 /(1-\eta)$ is the elasticity of substitution between consumption goods, and $1 /(1-\psi)$ is the elasticity of substitution between the consumption aggregate and leisure; $\theta_{i}^{j}$ and $\zeta_{j}$ are share parameters in household $j$ 's preferences; $t_{d}^{j}$ is the direct tax rate levied on household $j ; w_{j}$ is the wage rate for skilled or unskilled labor; $\bar{k}_{e, j}$ and $\bar{k}_{z, j}$ are the equipment and structures endowments of household $j$; and $r_{e}$ and $r_{z}$ are the rental rates for equipment and structures.

Additionally, $c_{i n v, j}$ denotes the purchases of the investment good by household $j$ and $p_{i n v}$ is its price. If the government runs a deficit, we assume that it sells government bonds to the households to finance the deficit. Thus, $c_{b, j}$ denotes the purchases of government bonds 
by household $j$. We follow Kehoe and Serra-Puche (1983) and assume that households treat government bonds and the investment good as perfect substitutes. Consequently, $c_{i n v, j}$ and $c_{b, j}$ account for the savings of household $j$.

\subsection{Government}

To account for the government purchases observed in the data, we follow the standard practice in the literature (see Whalley 1982 and Kehoe 1996) and model the government as a utility-maximizing agent that derives utility from consuming production goods and the investment good. The government imposes taxes to finance the purchases of consumption and services $c_{i, g}$. Additionally, if the government runs a surplus, it purchases the investment good, which we denote by $c_{i n v, g}$. Government consumption baskets are ranked according to the utility function:

$$
\sum_{i \in I} \theta_{i}^{g} \log c_{i, g}+\theta_{i n v}^{g} \log c_{i n v, g}
$$

These purchases must satisfy the government's budget constraint

$$
\begin{aligned}
\sum_{i \in I} p_{i} c_{i, g}+p_{i n v} c_{i n v, g} & =\sum_{j \in H} t_{d}^{j}\left(w_{j} \ell_{j}+r_{e} \bar{k}_{e, j}+r_{z} \bar{k}_{z, j}\right)+\sum_{i \in I} t_{i} p_{d, i} y_{d, i} \\
& +\sum_{i \in I} e \tau_{f, i} \bar{p}_{f, i} y_{f, i}+\sum_{j \in H} p_{i n v} c_{b, j}
\end{aligned}
$$

The left-hand side of the budget constraint includes purchases of goods and services, as well as the investment good. The first term in the right-hand side includes the direct taxes levied on the households; the second and third term denote production taxes and tariff revenues, respectively; the last term represents the sales of bonds to the households if the government runs a deficit, in which case, $c_{i n v, g}=0$.

\subsection{Rest of the World}

We model a single representative household in the rest of the world that purchases imported goods $x_{f, i}$ from the small open economy and also consumes its own local good $x_{f, f}$ to maximize utility

$$
\left[\sum_{i \in I} \theta_{i}^{f} x_{f, i}^{\rho_{x}}+\theta_{i n v}^{f} x_{f, i n v}^{\rho_{x}}+\theta_{f}^{f} x_{f, f}^{\rho_{x}}-1\right] / \rho_{x}
$$

subject to the budget constraint

$$
\sum_{i \in I}\left(1+\tau_{i}^{f}\right) p_{i} x_{f, i}+p_{i n v} x_{f, i n v}+e x_{f, f}=e I_{f}
$$


where $\tau_{i}^{f}$ is the ad-valorem tariff rate that the rest of the world imposes on its imports of commodity $i ; 1 /\left(1-\rho_{x}\right)$ is the export elasticity of substitution; $I_{f}$ is the income in the rest of the world; $e$ is the real exchange rate; and $x_{f, i n v}$ are purchases of the investment good in the small economy by the rest of the world, which account for the trade deficit in the small economy.

\subsection{Definition of Equilibrium}

An equilibrium for this economy consists of a set of prices $\left\{p_{i}\right\}_{i \in I}$ for the final goods; $\left\{p_{d, i}\right\}_{i \in I}$ for the domestic components; and $p_{i n v}$ for the investment good; factor prices $w_{s}, w_{u}$, $r_{e}, r_{z}$; an exchange rate $e$; foreign prices $\left\{\bar{p}_{f, i}\right\}_{i \in I}$; a consumption plan for each type of household $j\left(\left\{c_{i, j}\right\}_{i \in I}, c_{i n v, j}, c_{b, j}\right)$; a consumption plan for the government $\left(\left\{c_{i, g}\right\}_{i \in I}, c_{i n v, g}\right)$; a consumption plan for the household in the rest of the world $\left(\left\{x_{f, i}\right\}_{i \in I}, x_{f, i n v}, x_{f, f}\right)$; a production plan for the domestic-component producer of commodity $i\left(y_{d, i}, x_{1, i}, \ldots x_{n, i}, k_{e, i}, k_{z, i}, \ell_{u, i}, \ell_{s, i}\right)$; a production plan for the producer of commodity $i\left(y_{i}, y_{d, i}, y_{f, i}\right)$; and a production plan for the investment good firm $\left(y_{i n v}, x_{1, i n v}, \ldots, x_{n, i n v}\right)$; such that, given the tax rates and the tariff rates:

(i) The consumption plan $\left(\left\{c_{i, j}\right\}_{i \in I}, c_{i n v, j}, c_{b, j}\right)$ maximizes the utility of household $j$ subject to its budget constraint.

(ii) The consumption plan $\left(\left\{c_{i, g}\right\}_{i \in I}, c_{i n v, g}\right)$ maximizes the government's utility subject to its budget constraint.

(iii) The consumption plan $\left(\left\{x_{f, i}\right\}_{i \in I}, x_{f, i n v}, x_{f, f}\right)$ maximizes the utility of the household in the rest of the world subject to its budget constraint.

(iv) The production plan $\left(y_{d, i}, x_{1, i}, \ldots x_{n, i}, k_{e, i}, k_{z, i}, \ell_{u, i}, \ell_{s, i}\right)$ satisfies:

$$
\begin{aligned}
& y_{d, i}=\min \left\{\frac{x_{1, i}}{a_{1, i}}, \ldots, \frac{x_{n, i}}{a_{n, i}}, \beta_{i} k_{z, i}^{\alpha_{i}}\left[\lambda_{i}\left[\mu_{i} k_{e, i}^{\rho}+\left(1-\mu_{i}\right) \ell_{s, i}^{\rho}\right]^{\frac{\sigma}{\rho}}+\left(1-\lambda_{i}\right) \ell_{u, i}^{\sigma}\right]^{\frac{1-\alpha_{i}}{\sigma}}\right\} \\
& \text { and }\left(1-t_{p, i}\right) p_{d, i} y_{d, i}-\sum_{j \in I} p_{j} x_{j, i}-w_{u} \ell_{u, i}-w_{s} \ell_{s, i}-r_{e} k_{e, i}-r_{z} k_{z, i} \leq 0,=0 \text { if } y_{d, i}>0
\end{aligned}
$$

(v) The production plan $\left(y_{i}, y_{d, i}, y_{f, i}\right)$ satisfies:

$$
p_{i} y_{i}-p_{d, i} y_{d, i}-\left(1+\tau_{f, i}\right) e \bar{p}_{f, i} y_{f, i} \leq 0,=0 \text { if } y_{i}>0
$$

where $y_{d, i}$ and $y_{f, i}$ solve:

$$
\min p_{d, i} y_{d, i}+\left(1+\tau_{f, i}\right) e \bar{p}_{f, i} y_{f, i} \quad \text { s.t. } \phi_{i}\left[\delta_{i} y_{d, i}^{\rho_{m, i}}+\left(1-\delta_{i} y_{f, i}^{\rho_{m, i}}\right]^{\frac{1}{\rho_{m, i}}}=y_{i}\right.
$$


(vi) The production plan $\left(y_{i n v}, x_{1, i n v}, \ldots, x_{n, i n v}\right)$ satisfies:

$$
\begin{gathered}
y_{i n v}=\min \left\{\frac{x_{1, i n v}}{a_{1, i n v}}, \ldots, \frac{x_{i, i n v}}{a_{i, i n v}}, \ldots, \frac{x_{n, i n v}}{a_{n, i n v}}\right\} \\
\text { and } p_{i n v} y_{i n v}-\sum_{j \in I} p_{j} x_{j, i n v} \leq 0,=0 \text { if } y_{i n v}>0
\end{gathered}
$$

(viii) The factor markets clear:

$$
\sum_{i \in I} \ell_{u, i}=\ell_{u} ; \quad \sum_{i \in I} \ell_{s, i}=\ell_{s} ; \quad \sum_{i \in I} k_{e, i}=\sum_{j \in H} \bar{k}_{e, j}=\bar{K}_{e} ; \quad \sum_{i \in I} k_{z, i}=\sum_{j \in H} \bar{k}_{z, j}=\bar{K}_{z}
$$

(ix) The goods markets clear:

$$
\begin{gathered}
y_{i}=\sum_{j \in I} x_{j, i}+x_{i, i n v}+\sum_{j \in H} c_{i, j}+c_{i, g}+x_{f, i} \quad \forall i \in I \\
y_{i n v}=\sum_{j \in H} c_{i n v, j}+c_{i n v, g}+x_{f, i n v}
\end{gathered}
$$

(x) The balance of payments condition is satisfied:

$$
\sum_{i \in I} e \bar{p}_{f, i} y_{f, i}=\sum_{i \in I} p_{i} x_{f, i}+p_{i n v} x_{f, i n v}
$$

\subsection{The Skill Premium in the Model}

From the first-order conditions of the firm that produces the domestic component $y_{d, i}$, we can derive the expression for the skill premium, which we denote as $\pi$ :

$$
\begin{aligned}
\pi=\frac{w_{s}}{w_{u}} & =\frac{\lambda_{i}\left(1-\mu_{i}\right)}{1-\lambda_{i}} \quad\left[\mu_{i} k_{e, i}^{\rho}+\left(1-\mu_{i}\right) \ell_{s, i}^{\rho}\right]^{\frac{\sigma-\rho}{\rho}} \frac{\ell_{s, i}^{\rho-1}}{\ell_{u, i}^{\sigma-1}} \\
& =\frac{\lambda_{i}\left(1-\mu_{i}\right)}{1-\lambda_{i}}\left[\mu_{i}\left(\frac{k_{e, i}}{\ell_{s, i}}\right)^{\rho}+\left(1-\mu_{i}\right)\right]^{\frac{\sigma-\rho}{\rho}}\left(\frac{\ell_{s, i}}{\ell_{u, i}}\right)^{\sigma-1}
\end{aligned}
$$

Log-linearizing (10) and differentiating with respect to time, we obtain the following expression, similar to the one found in Krusell et al. (2000):

$$
\gamma_{\pi} \simeq \mu_{i}(\sigma-\rho)\left(\frac{k_{e, i}}{\ell_{s, i}}\right)^{\rho}\left(\gamma_{k_{e, i}}-\gamma_{\ell_{s, i}}\right)+(\sigma-1)\left(\gamma_{\ell_{s, i}}-\gamma_{\ell_{u, i}}\right) \quad \forall i \in I
$$

where $\gamma_{x}$ denotes the growth rate of variable $x$. As in Krusell et al. $(2000)$, the growth rate 
of the skill premium depends on the relative growth rates of equipment capital and skilled labor, captured by the first term in (11), and the relative growth rates of skilled and unskilled labor, captured by the second term. Additionally, as our model includes sectors that differ in their skill intensities, the growth rate of the skill premium also depends on the cross-sector reallocation of factors. This is the $\mathrm{H}-\mathrm{O}$ mechanism, whereby reductions in trade costs lead to shifts in factors of production towards the sectors where the country displays comparative advantages. This in turn raises the return of the factor that is used more intensively in those sectors.

\section{Application to the Baltic States}

We now want to assess whether our model generates predictions that are in line with actual data observations. To do so, we use our framework to account for the patterns of the skill premium in the Baltic states: Estonia, Latvia and Lithuania. Since we believe these countries present an interesting application, we document the patterns of the skill premium in the three economies, followed by a comparison of trade, capital stock, and demographic trends.

\subsection{The Skill Premium}

We construct skill premium series using the data in the Socio Economic Accounts (SEA) section of the World Input Output Database (WIOD). Our definition of skill is by educational attainment: skilled workers are those who have tertiary education, while unskilled workers are those who do not $2^{2}$ The SEA database does not contain readily-available skill premium series for the Baltic states, but it includes series of both labor compensation and hours worked, disaggregated by skill levels. This allows us to back out the skill premium series using the fact that:

$$
\text { skill premium }=\frac{w_{s}}{w_{u}}=\frac{\frac{w_{s} \ell_{s}}{\ell_{s}}}{\frac{w_{u} \ell_{u}}{\ell_{u}}}
$$

where $\ell_{s}$ and $\ell_{u}$ are hours worked by skilled and unskilled labor, and $w_{s} \ell_{s}$ and $w_{u} \ell_{u}$ are skilled and unskilled labor compensation, all of which are available in the WIOD.

The constructed skill premium series start in 1995, the first year for which of data are availabile in the WIOD, and end in 2008, the year prior to the international financial crisis.

\footnotetext{
${ }^{2}$ The definition of "skill" is not standard in the literature and has been used to denote the occupation, sector, or even tenure of different types of workers. In this article, we follow Goldin and Katz (2008) and Krusell et al. (2000) and use the educational-attainment definition of skill: skilled workers are those with tertiary (or college) education, while unskilled workers are those with non-tertiary education.
} 
They are shown in Figure 1, both in absolute terms and also normalized so that they take the value of 100 in the initial year, to facilitate comparisons. A few points are worth noting: the first is that in 1995, the skill premium exhibited quite similar values in all three Baltic states. Second, despite this initial similarity, the Baltic skill premia took divergent paths: by 2008, the skill premium in Latvia had increased by approximately $16 \%$ from its 1995 value, while the skill premium in Estonia and Lithuania had declined by around $20 \%$ and $13 \%$ during the same period, respectively.
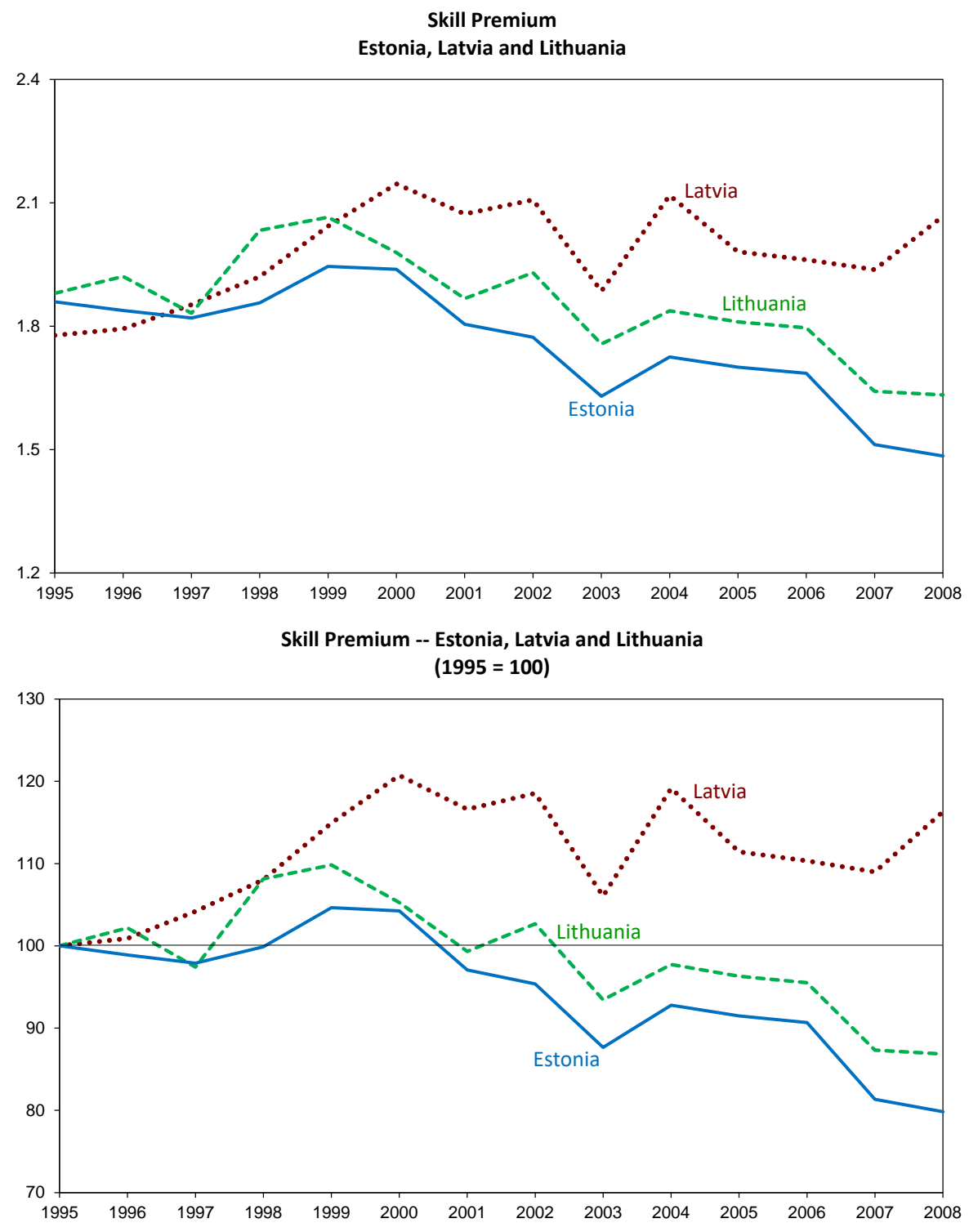

Figure 1: Skill premium in the Baltic states in absolute terms (top) and normalized, $1995=100$ (bottom) 


\subsection{The Stock of Capital}

As documented in Bems and Jönsson Hartelius (2006), upon their independence the Baltic states were capital-poor economies when compared to their peers in the European Union. Since then, they have all expanded their stocks of capital quickly, both in the form of structures and of equipment.
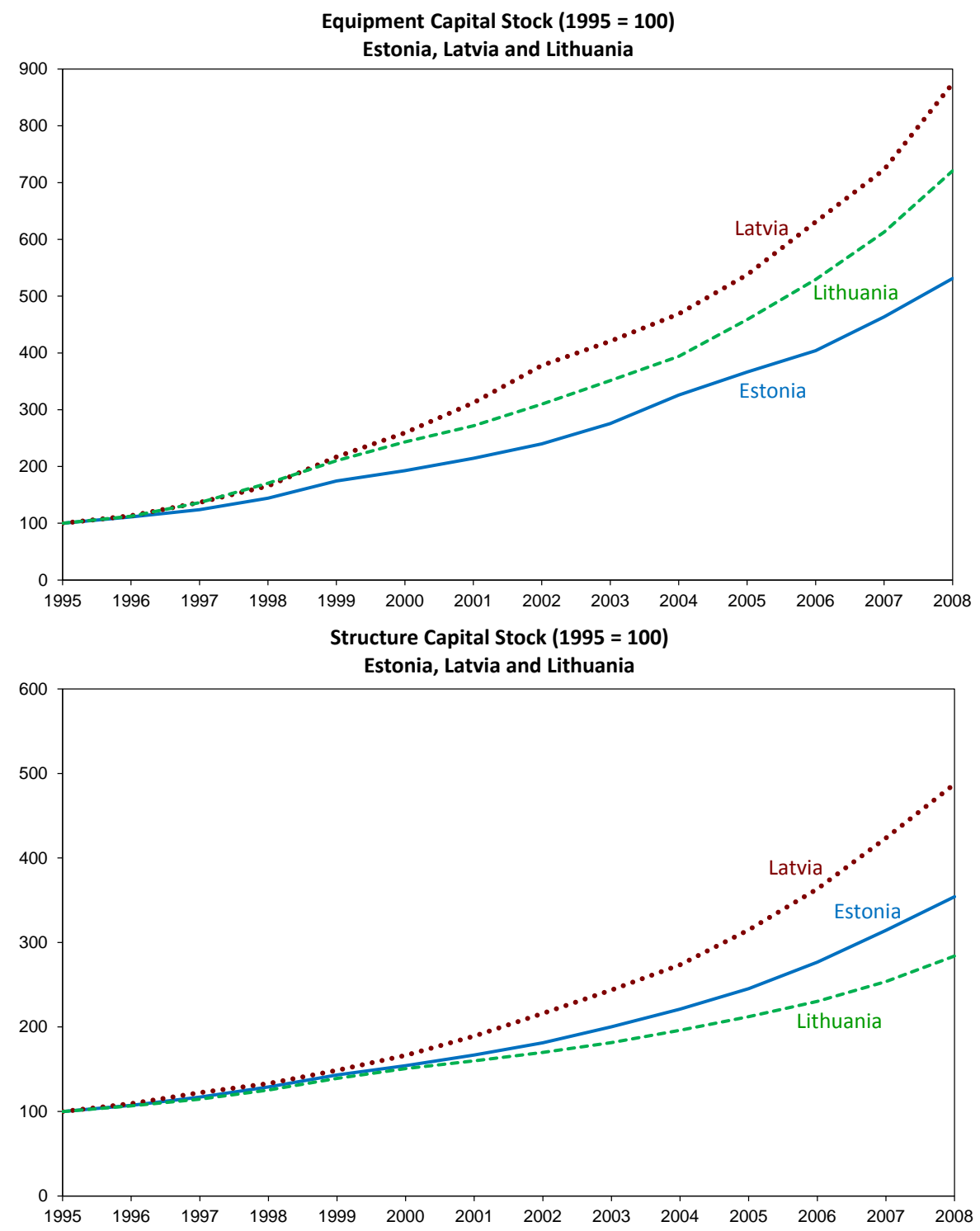

Figure 2: Equipment (top) and structures (bottom) capital stocks in the Baltic states, $1995=100$

Using the OECD National Accounts database, we construct time series for the equipment and structures capital stock for Estonia, Latvia and Lithuania.$^{3}$ We find that both types

\footnotetext{
${ }^{3}$ In Section 5.1 we explain in more detail how we construct the capital stock series.
} 
of capital grew at very fast rates in all three countries, with Latvia displaying the highest growth rate for equipment capital stock, which is the type of capital that is considered to be complementary to skilled labor. Moreover, the share of equipment capital in the total stock of capital was also the highest in Latvia.

\subsection{Skill Composition of the Population}
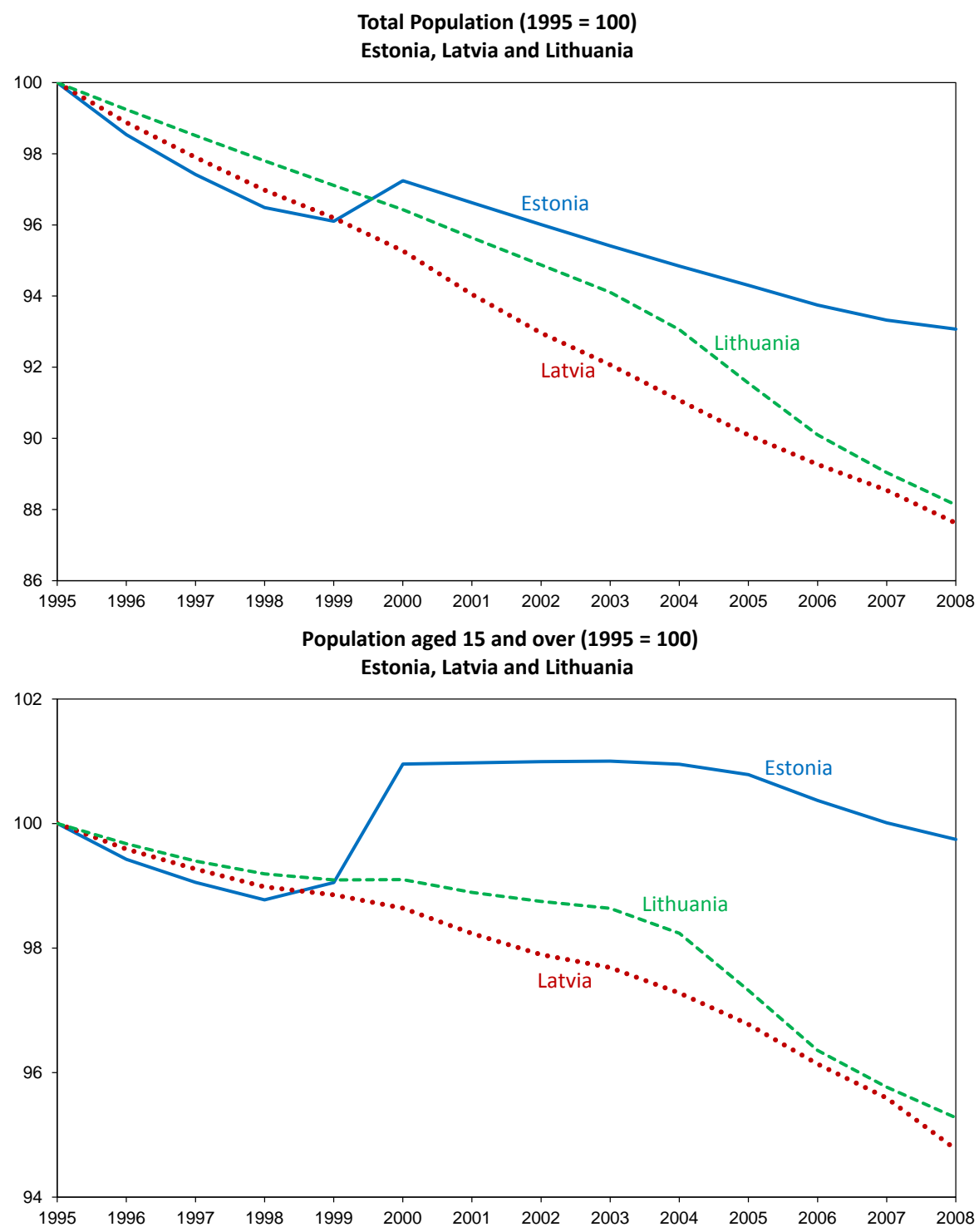

Figure 3: Total population (top) and population aged 15 and over (bottom) in the Baltic states, $1995=100$

The populations of the Baltic states are among the smallest in the European Union, with Estonia's population a little over 1 million, and Latvia's and Lithuania's around the 2and 3-million mark, respectively. As Figure 3 shows, all three countries exhibited persistent population declines: between 1995 and 2008, Estonia's population shrank by 7\%, while 
the populations of Latvia and Lithuania declined by approximately $12 \%$. For Latvia and Lithuania, the decline in the total population was coupled with a decline in the population aged 15 and over (which includes those who are of working age) of nearly $5 \%$ during the same period. In Estonia, this segment of the population remained relatively constant, with small fluctuations above and below the 1995 levels 4
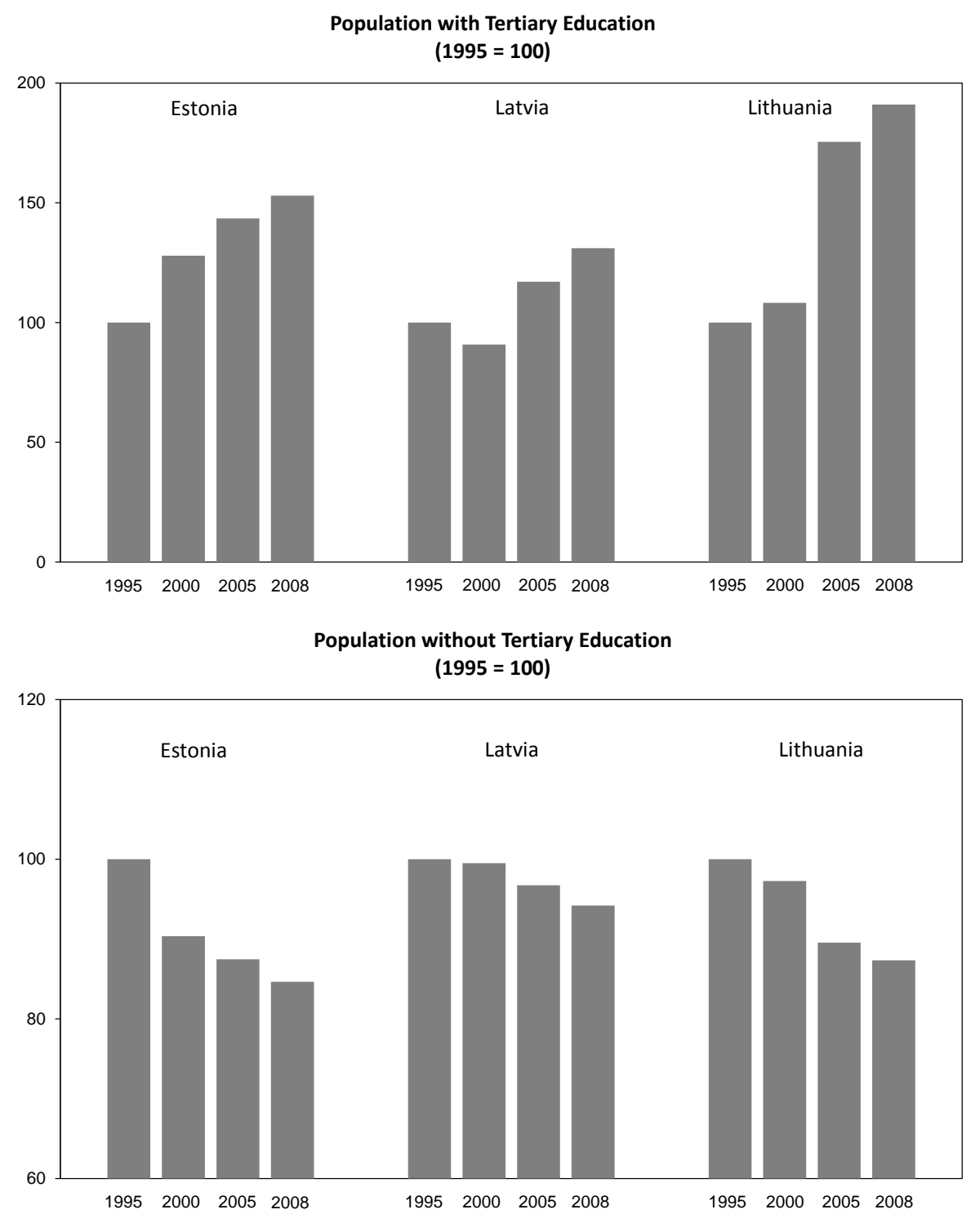

Figure 4: Population aged 15 and over with tertiary education (top) and with non-tertiary education (bottom), $1995=100$

Additionally, as depicted in Figure 4, the skill composition of the Baltic population changed substantially, with the population with tertiary education growing and the number

\footnotetext{
${ }^{4}$ Data are taken from the World Bank's World Development Indicators database.
} 
of those without it declining. The Barro and Lee (2013) database reveals that the changes in the composition of the population aged 15 and over were uneven across the BalticsLithuania displayed the largest increase in the skilled population, followed by Estonia and then by Latvia. At the same time, Latvia recorded the smallest decline in the unskilled population, followed by Lithuania and Estonia. [ $^{2}$

\subsection{The Foreign Sector}

The three Baltic states have displayed high degrees of openness - measured as the ratio of total trade to GDP - ever since opening their economies. As small and very open economies, the Baltics are obviously exposed to variations in their terms of trade (defined as the ratio of export prices to import prices). Using the Annual Macro-economic Database (AMECO) compiled by the European Commission, we calculate the series of terms of trade for goods and for services during the 1995-2008 period. A clear divergent pattern is evident for the terms of trade for goods, as Estonia and Lithuania experienced improvements in the terms of trade, whereas Latvia experienced a decline. In contrast, all three countries enjoyed improvements in the terms of trade in the services sector, but they were of much larger magnitudes in Estonia and Lithuania than in Latvia (see Figure 5).

\section{Calibration}

Most of the parameters specific to each Baltic economy - such as the input shares and total factor productivity scale parameters in the production functions, as well as the parameters in the agents' utility functions - can be directly calibrated from a social accounting matrix (SAM) by using the optimality and market clearing conditions and by choosing physical units such that prices - including factor prices - are equal to one in the base case. Thus, a central step in the calibration exercise is the construction of a SAM for each Baltic state ${ }^{6}$ To build the matrices, we work with data from the WIOD using 1995 as the base year to coincide with the initial year of the period we analyze.

\footnotetext{
${ }^{5}$ The Barro and Lee (2013) database reports statistics in five-year intervals. For the period we analyze, the database provides information for the years 1995, 2000, 2005 and 2010. The values for the year 2008 were calculated by linear interpolation.

${ }^{6} \mathrm{~A}$ SAM is a record of all the transactions that take place in an economy during a given period of time, typically one year. It provides a snapshot of the structure of production, where the row entries record the receipts of a particular agent and the column entries represent the payments made by the agents. Depending on data availability, it can provide a highly disaggregated level of institutional detail, with different types of firms, various levels of government, households that differ in basic demographic characteristics, and multiple trade partners.
} 
Sectoral aggregation. Each Baltic state is modeled as the small open economy described in Section 2, which is composed of two sectors: goods and services. In Appendix 1 we detail how we assigned all the industries in the WIOD's input-output tables to the two sectors of our model. In Appendix 1 we also report the skill intensity of each sector, measured by the share of hours worked by skilled workers.7 We find that the average skill intensity in the services sector for all three countries is approximately three times higher than the corresponding average in the goods sector. Consequently, in what follows we use the terms "goods sector" and "unskilled-labor intensive sector" interchangeably, as we do for the terms "services sector" and "skilled-labor intensive sector."

Households classification and expenditures disaggregation. The WIOD allows us to build a SAM with a single aggregate household, but provides limited information on how to group households by skill type. To do so, we use Household Budget Surveys (HBS) from each Baltic state. These surveys contain data on household expenditures, savings and income according to the level of educational attainment of the head of the household. This allows us to group households' expenditures on goods and services, as well as total income, in two categories: one for "high skilled" — or simply "skilled" workers, who are those with tertiary education - and the other for "low skilled," or "unskilled" workers, who are those without.

Value added disaggregation. The SEA data allow us to split the aggregate labor compensation component of value added for each sector into skilled and unskilled labor compensation. However, the WIOD only contains the aggregate capital income component of value added, but it does not offers a breakdown of the different types of capital stock. To split this component into equipment and structures capital, we use data from the OECD National Accounts database (more details are provided in Section 5). Both types of capital income are distributed between skilled and unskilled households to match the average income ratios found in the HBS data.

Calibration. The resulting SAMs for Estonia, Latvia and Lithuania for the year 1995 can be found in Appendix 2. With the SAMs in hand, we can proceed to calibrate the model's parameters. For example, dividing the first order condition for equipment capital by the one for skilled labor for the domestic component firm in sector $i$ yields:

$$
\frac{r_{e}}{w_{s}}=\frac{\mu_{i} k_{e, i}^{\rho-1}}{\left(1-\mu_{i}\right) \ell_{s, i}^{\rho-1}}
$$

\footnotetext{
${ }^{7}$ Those data are taken from the WIOD's SEA, which contain industry-level data on employment, including the number of workers and their educational attainments.
} 
Using the first order conditions again, and setting $w_{s}=1$ and $r_{e}=1$ implies:

$$
\frac{r_{e} k_{e, i}}{w_{s} \ell_{s, i}}=\left(\frac{\mu_{i}}{1-\mu_{i}}\right)^{\frac{1}{1-\rho}}
$$

The numerator on the left-hand side is equipment capital income in sector $i$, and the denominator is skilled labor income in that sector. Those numbers can be found in the SAM. For the unskilled intensive goods sector in Estonia in 1995, we have:

$$
\frac{50.0}{131.1}=\left(\frac{\mu_{G}}{1-\mu_{G}}\right)^{\frac{1}{1-\rho}}
$$

Setting $\rho=-0.5$ (we explain the values we choose for the elasticities in more detail below), gives us $\mu_{G}=0.191$. All the calibrated parameters are shown in Appendix 3 .

Labor/leisure data. Since our model incorporates a labor-leisure choice, we model each household as being endowed with a maximum number of available hours, assumed to be 5200 per year (100 hours per week $\times 52$ weeks per year). We then multiply the total endowment of time per worker by the number of workers of type $j 8^{8}$ The resulting value corresponds to $\bar{L}_{j}$ in the model. Moreover, the SEA include information on total hours worked in each sector, together with the fraction of skilled and unskilled hours worked in each sector. This lets us to back out the total hours devoted to leisure as the difference between the total time endowment and the total hours worked by each type of worker.

Parameter values taken from external sources. Finally, some parameters in the model cannot be calibrated directly from the SAMs or other external data. In those instances we assign values that are commonly used in the literature. These values are summarized in Table 1 and are the ones we use in our benchmark experiments.

We set $\rho_{m, i}$, the parameter that governs the import elasticity of substitution in sector $i$, to take the value of 0.827 . This is the average of $0.844,0.758$ and 0.879 , which are the values estimated in Ruhl (2008), Simonovska and Waugh (2014), and Eaton and Kortum (2002), respectively. Our choice of $\rho_{m, i}$ implies an import elasticity of substitution of 5.78$]^{9}$

\footnotetext{
${ }^{8}$ Since the Socio Economic Accounts only provide the total number of workers, we determine the number of skilled and unskilled workers using the International Labor Organization (ILO) database on employment.

${ }^{9}$ Due to the lack of estimates of sectoral elasticities for the Baltic states, we use the same value for all sectors.
} 
Table 1: Parameters and Elasticity Values

\begin{tabular}{cclc}
\hline Parameter & Value & Corresponding Elasticity & Elasticity $(\varepsilon)$ \\
\hline$\rho_{m, i}$ & 0.827 & Import elasticity of substitution & 5.78 \\
$\rho_{x}$ & 0.9 & Export elasticity of substitution & 10 \\
$\rho$ & -0.5 & Equipment-skilled labor elasticity & 0.67 \\
$\sigma$ & 0.4 & Equipment-unskilled labor elasticity & 1.67 \\
$\eta$ & -1 & Consumption goods elasticity of substitution & 0.5 \\
$\psi$ & -0.25 & Consumption-leisure elasticity of substitution & 0.8 \\
\hline
\end{tabular}

Similarly, the export elasticity of substitution $\varepsilon_{x}$ is set at 10 (or $\rho_{x}=0.9$ ), a value in the middle of the range of estimates for this parameter in the literature.

We follow Krusell et al. (2000) and assume that the elasticity of substitution between equipment capital (or skilled labor) and unskilled labor is higher than the elasticity of substitution between equipment and skilled labor. Thus, we set $\rho$, the parameter that governs the latter elasticity to -0.5 , and $\sigma$, the parameter that determines the former, to 0.4 . Having $\sigma>\rho$ reflects the capital-skill complementarity assumption ${ }^{10}$ In our case, the corresponding elasticities of substitution for equipment-skilled labor and equipment-unskilled labor are set at 0.67 and 1.67 , respectively.

Lastly, the parameter $\eta$ determines the elasticity of substitution between the different consumption and investment goods in the utility function of the household. Following Stockman and Tesar (1995), we set $\eta=-1$ so that the elasticity of substitution between consumption goods is equal to 0.5. Moreover, we follow Auerbach and Kotlikoff (1987) and choose $\psi=-0.25$, which yields an elasticity of substitution between consumption and leisure of 0.8 , a value close to the estimate of Ghez and Becker 1975) ${ }^{11}$

\section{Numerical Experiments and Benchmark Results}

The calibrated model economies replicate the transactions recorded in the 1995 SAMs, which in our analysis represent the original equilibrium in each Baltic state. We next subject each economy to a series of shocks that incorporate the stylized facts documented in Section 3. This allows us to answer two questions: how would the different labor markets - and more specifically, the skill premium - in our model react if these shocks were to occur individually?

\footnotetext{
${ }^{10}$ When $\sigma=\rho \rightarrow 0$, the nested CES component in equation 2 becomes a Cobb-Douglas form with no complementarity between capital and skilled labor. We test the implications of that set of values in the sensitivity analysis section.

11 Auerbach and Kotlikoff (1987) run a robustness check with $\psi=-1.5$, which implies a lower elasticity of substitution of 0.4 . We try that case in the sensitivity analysis section, as well as the case of $\psi \rightarrow 0$, which yields a unit elasticity utility function.
} 
And what if they all were to operate simultaneously? Before going over the results, we describe the nature of the experiments we conduct in more detail. The exact values we use for the shocks are reported in Table 15 in Appendix 5.

\subsection{Numerical Experiments}

Changes in the terms of trade (ToT) experiment. In Section 3 we showed that, even though the Baltics are all quite open economies, their terms of trade took divergent paths. In the goods sector, both Estonia and Lithuania experienced improvements in their terms of trade between 1995 and 2008, while the opposite took place in Latvia, where its terms of trade deteriorated during the same period. We explore whether these diverging patterns in the terms of trade can account for the divergence of the skill premium. To do so, we allow the prices of the foreign components used in final production $\left(\bar{p}_{f, i}\right.$, which as small economies the Baltics take as exogenous) to vary so that, coupled with all other prices at their baseline levels, they result in the terms of trade changing by the same proportion as reported in the European Commission's AMECO database.

Equipment capital deepening experiment. Measures of capital stock decomposed by type are not readily available for the Baltics. However, the OECD National Accounts database presents Gross Fixed Capital Formation series disaggregated by type of capital for all three Baltic states. This allows us to construct structures and equipment capital stock series ${ }^{12}$ using the perpetual inventory method, which states that capital follows the law of motion:

$$
K_{i, t+1}^{n}=\left(1-\delta_{i}^{n}\right) K_{i, t}^{n}+I_{i, t}^{n}
$$

where $K_{i, t}^{n}$ is the stock of capital of type $i$ in period $t$ in country $n$; and $\delta_{i}^{n}$ and $I_{i, t}^{n}$ are the depreciation rate and investment in the corresponding type of capital and country in period $t$. To compute the initial level of each type of capital stock in each country -in our case, 1995 - we follow Hall and Jones (1999) and Caselli (2005) and set $K_{i, 1995}^{n}=I_{i, 1995}^{n} /\left(g_{i}^{n}+\delta_{i}^{n}\right)$, where $g_{i}^{n}$ is the average growth rate of investment of type- $i$ capital in country $n$.

After constructing the capital stocks series, the equipment capital deepening experiment consists in increasing the total stock of capital equipment $\bar{K}_{e}$ and capital structures $\bar{K}_{z}$ to match those observed in the data. Note that in this simulation we increase both types of capital but, as the literature has previously established, what is really complementary to skilled labor is equipment capital and not necessarily the total stock of capital. That

\footnotetext{
${ }^{12}$ We group "transport equipment," "ICT equipment" and "other machinery and equipment and weapon system" into a category we call "equipment capital," and "dwellings" and "other building structures" into a category we label as "structure capital."
} 
is why we refer to this experiment as "equipment capital deepening," since we expect the changes in the skill premium to be driven mostly by changes in equipment capital. Since the growth rates for equipment capital varied substantially across the Baltic states, we expect countries that experienced higher growth rates of equipment capital expansion to display higher increases in demand for skilled labor as well, and in turn larger increases in the skill premium.

Changes in the relative skill composition of the labor supply experiment. As mentioned earlier, all three Baltic states experienced similar demographic trends: shrinking populations coupled with increases in the number of college graduates. Using the data in Barro and Lee (2013), we first calculate series for the total number of skilled and unskilled workers between 1995 and 2008. Those series allow us to compute the changes in the relative skill composition of the labor supply for each country. We find that although the trends were similar in qualitative terms, the specific growth rates were quite uneven: between 1995-2008, Lithuania led the group with a $91 \%$ increase in the population aged 15 and over with tertiary education (which corresponds to our definition of skilled workers), compared to increases in Estonia and Latvia of $53 \%$ and $31 \%$, respectively. Similarly, although the unskilled population declined in all three countries, the changes varied significantly across the Baltics: Estonia saw the largest decrease in its unskilled population with a $15.3 \%$ decline, compared to the $12.7 \%$ and $5.8 \%$ decreases in Lithuania and Latvia, respectively. Thus, Latvia exhibited the smallest increase in the skilled population and the smallest decrease in the unskilled population among the Baltic states. In these numerical experiments, we use these trends in labor supply composition to re-calibrate the values of $\bar{L}_{u}$ and $\bar{L}_{s}$, the total available number of unskilled and skilled hours, and examine how the observed increases in skilled labor supply and decreases in unskilled labor supply affected the skill premium.

\subsection{Benchmark Results}

\subsubsection{Effects of the changes in the terms of trade}

As noted earlier, the Baltic states experienced divergent changes in their terms of trade. Estonia and Lithuania recorded improvements in the terms of trade across all sectors, with the skilled-labor intensive services sector benefiting more than the unskilled-labor intensive goods sectors. On the other hand, the Latvian terms of trade in the goods sector worsened, while they improved for the services sector (which has a smaller weight in overall trade volume).

As shown in Table 2 below, as a response to changes in the terms of trade our model generates trade increases - both exports and imports - in both sectors for Estonia and Lithuania, while in Latvia trade declines in the goods sector and increases in the services sector. These 
trade changes translate into final production changes in all three countries, with final output increasing in Estonia and Lithuania, and decreasing in Latvia. With output rising, wages go up in the first two countries, while they fall in Latvia.

Table 2: Benchmark Results: Effects of Changes in the Terms of Trade (percent change)

\begin{tabular}{llrrr}
\hline Variable & Type/Sector & Estonia & Latvia & Lithuania \\
\hline Skill premium & & -2.2 & -1.9 & -1.3 \\
Wage & Skilled labor & 10.8 & -4.0 & 20.2 \\
& Unskilled labor & 13.3 & -2.1 & 21.7 \\
Imports & Unskilled sector & 88.5 & -39.1 & 274.3 \\
& Skilled sector & 333.8 & 56.4 & 621.6 \\
Exports & Unskilled sector & 116.6 & -33.5 & 319.9 \\
\multirow{3}{*}{ Final output } & Skilled sector & 63.5 & 0.7 & 16.5 \\
& Unskilled sector & 34.9 & -6.4 & 89.4 \\
Domestic output & Skilled sector & 6.0 & -1.1 & 4.6 \\
& Unskilled sector & 9.4 & 7.4 & 5.0 \\
\multirow{2}{*}{ Unskilled labor demand } & Skilled sector & -4.8 & -2.8 & -3.8 \\
& Unskilled sector & 7.6 & 6.7 & 3.0 \\
Skilled labor demand & Skilled sector & -7.3 & -4.1 & -6.1 \\
& Unskilled sector & 11.5 & 9.2 & 5.7 \\
& Skilled sector & -3.9 & -1.5 & -3.8 \\
\hline
\end{tabular}

As for the effects on the skill premium, all three countries uniformly experience a small decrease in their skill premium, with the largest decline taking place in Estonia (2.2\%) and the smallest one in Lithuania (1.3\%). This declining pattern in the skill premium is due to larger increases in unskilled wages than in skilled wages for Estonia and Lithuania, whereas in Latvia is the result of skilled wages falling further than unskilled wages.

To understand why both positive and negative trade shocks lead to the same qualitative effect on the skill premium in all three countries, we examine the patterns of sectoral reallocation of resources by looking at the changes in domestic production and demand for both types of labor in each sector. In Estonia and Lithuania, labor shifts from the skilled-labor intensive services sector toward the unskilled-labor intensive goods sector. In turn, domestic production of goods increases. This is the H-O mechanism in action, where countries respond to a positive trade shock by shifting their resources to increase exports in the sectors in which they enjoy comparative advantages 13 In Latvia, on the other hand, labor shifts to

\footnotetext{
${ }^{13}$ The data suggest that the Baltic states have comparative advantages in sectors that are unskilledintensive. For example, during the 1995-2008 period, sectors such as wood products, textiles, foodstuffs, and animal products display values for the Revealed Comparative Advantage (RCA) index that are well
} 
increase the production of the domestic component in the goods sector, in order to substitute the imported component which had become more expensive as a result of the negative trade shock in that sector.

\subsubsection{Effects of equipment capital deepening}

The largest increase in the Baltics in equipment capital between 1995 and 2008 took place in Latvia, where it rose by a factor of nearly eight. Meanwhile, the expansions in equipment capital in Estonia and Lithuania were comparatively smaller. Indeed, when we feed in the observed increases in both types of capital, our model generates the largest increase in the skilled relative wage for Latvia, where it goes up by $49.3 \%$, followed by Lithuania and Estonia, where the skill premium increases by $28.9 \%$ and $27.0 \%$, respectively. The effects of changes in the stock of capital equipment are shown in Table 3.

Table 3: Benchmark Results: Effects of Changes in Equipment Capital (percent change)

\begin{tabular}{llrrr}
\hline \multirow{2}{*}{ Variable } & Type/Sector & Estonia & Latvia & Lithuania \\
\hline Skill premium & & 27.0 & 49.3 & 28.9 \\
Wage & Skilled labor & 82.9 & 175.8 & 114.2 \\
& Unskilled labor & 44.0 & 84.8 & 66.2 \\
Rental price & Equipment capital & -85.7 & -88.1 & -88.3 \\
Final output & Unskilled sector & 42.3 & 83.2 & 60.7 \\
& Skilled sector & 51.5 & 97.3 & 68.7 \\
Domestic output & Unskilled sector & 49.9 & 96.9 & 74.7 \\
\multirow{2}{*}{ Equipment capital demand } & Unskilled sector & 494.9 & 1064.5 & 799.4 \\
& Skilled sector & 409.3 & 671.7 & 544.9 \\
Unskilled labor demand & Unskilled sector & -3.1 & -10.5 & -10.8 \\
& Skilled sector & -1.7 & -6.4 & -4.0 \\
Skilled labor demand & Unskilled sector & 8.9 & 42.9 & 29.3 \\
& Skilled sector & -6.7 & -5.3 & -7.3 \\
\hline
\end{tabular}

To disentangle the forces driving these changes in the skill premium, we analyze the changes in the relevant variables reported in the table. First, the increases in the stock of capital drive down the rental prices of capital which in turn raise the demand for capital in all sectors. Second, larger stocks of capital allow both domestic and final output to increase in all sectors. Third, capital deepening - and more specifically, equipment capital deepeningaffects the demands for the two types of labor differently, favoring skilled over unskilled

in excess of unity, while skill-intensive sectors such as machinery and electrical equipment and transport equipment exhibit RCA values below 1 . 
labor. As implied by equation (11), the skill premium rises for all three countries, and we find that this is due to the wage of skilled labor rising faster than that of unskilled labor. Finally, capital deepening and the resulting changes in relative wages generate reallocation of labor both across and within sectors. For example, demand falls in the skilled-intensive services sector for both types of labor, while in the unskilled-intensive goods sector demand goes up for the skilled labor and declines for the unskilled labor.

\subsubsection{Effects of changes in the skill composition of the labor supply}

Table 4: Benchmark Results: Effects of Changes in the Skill Composition of the Labor Supply (percent change)

\begin{tabular}{llrrr}
\hline Variable & Type/Sector & Estonia & Latvia & Lithuania \\
\hline Skill premium & & -41.5 & -28.2 & -53.6 \\
Wage & Skilled labor & -30.1 & -23.2 & -45.1 \\
\multirow{3}{*}{ Final output } & Unskilled labor & 19.5 & 7.1 & 18.3 \\
& Unskilled sector & 2.9 & 0.1 & 4.1 \\
Domestic output & Skilled sector & 9.0 & 4.3 & 11.7 \\
& Unskilled sector & 1.4 & -1.1 & 2.6 \\
& Skilled sector & 9.6 & 4.6 & 12.1 \\
Hours worked & All sectors & 6.9 & 2.9 & 8.9 \\
& Unskilled labor & -21.8 & -4.7 & -8.5 \\
\multirow{4}{*}{ Unskilled labor demand } & Skilled labor & 58.7 & 29.4 & 84.4 \\
\multirow{2}{*}{ Skilled labor demand } & Total labor & 16.7 & 4.4 & 30.6 \\
& Skilled sector & -16.8 & -6.8 & -12.6 \\
& Unskilled sector & 64.8 & -11.2 & -27.3 \\
& Skilled sector & 57.4 & 34.5 & 100.9 \\
\hline
\end{tabular}

Table 4 shows the effects of the labor supply shock. Although the effects on hours worked by different skill types are mixed, total hours worked rise for all three countries. Therefore, skill composition changes - or "skill-upgrading" of labor force - lead to increases in final production in all sectors, as well as in aggregate domestic production. In spite of this positive impact on aggregate output, we observe differentiated effects on the factors of production. As unskilled labor became scarcer, its wage surges, while the opposite occurs for skilled labor. This effectively lowers the skill premium in all three countries. Finally, the changes in the relative wages translate into increases in the demand for skilled workers and decreases in the demand for unskilled workers across all sectors. 


\subsubsection{Joint simulation results}

To summarize, the individual experiments yield the following results: the terms of trade shocks lower the skill premium across the Baltics, with Estonia experiencing the largest decline and Lithuania the smallest one. Equipment capital deepening increases the skill premium, with Latvia recording the largest surge and Estonia and Lithuania smaller but comparable increases. Finally, changes in the skill composition of the labor supply lead to sizable decreases in the skill premium across the three countries, with the smallest fall in Latvia and larger and similarly-sized drops in Estonia and Lithuania.

The joint simulation incorporates all three shocks simultaneously, and the results are presented in Table 5. Including all three shocks generates decreases in the skill premium in Estonia and Lithuania by $-22.4 \%$ and $-35.3 \%$ respectively, which match the changes observed in the data qualitatively, and quantitatively for Estonia. For Latvia, our model predicts an increase of $9.8 \%$ in the skill premium, closely replicating the observed growth in Latvian relative wages. The joint experiment allows us to assess the net effects of labor demand and labor supply shocks: in Latvia, the demand shocks dominate the supply one, whereas in Estonia and Lithuania the supply shock dominates the demand effects.

Table 5: Benchmark Results: Joint Simulation (percent change)

\begin{tabular}{lrrr}
\hline Variable & Estonia & Latvia & Lithuania \\
\hline Skill premium (data) & -20.2 & 16.3 & -13.1 \\
Skill premium (joint simulation) & -22.4 & 9.8 & -35.3 \\
$\quad$ Skilled wage & 50.1 & 117.1 & 52.7 \\
$\quad$ Unskilled wage & 93.4 & 97.6 & 136.0 \\
\hline Skill premium (ToT only) & -2.2 & -1.9 & -1.3 \\
Skill premium (capital deepening only) & 27.0 & 49.3 & 28.9 \\
Skill premium (skill composition only) & -41.5 & -28.2 & -53.6 \\
Sum of individual effects & -16.7 & 19.2 & -26.0 \\
\hline
\end{tabular}

Lastly, we find that the joint effects of all three factors taken into account simultaneously can be quantitatively different from just the sum of the single-factor results. Indeed, in equation (11), we pointed out that the capital-skill complementarity effect depends on the growth rate of equipment capital per skilled worker. This implies that an increase in the supply of skilled workers would not only lower the skill premium through the labor supply channel but also dampen the effect of capital equipment growth on the increases in the skill premium. Taking the interaction between all three factors into account, the changes in the skill premium are quantitatively smaller than the sum of single-factor outcomes by 5.7 percentage points for Estonia, 9.4 for Latvia and 9.3 for Lithuania. 


\section{Sensitivity Analyses}

\subsection{Skill Premium Patterns at Intermediate Horizons}

Our model can account well for the changes in the skill premium over the whole period 1995-2008. The next natural question is whether it can also account for the skill premium patterns within that time span since the evolution of the skill premium in the data is nonmonotonic. More precisely, the skill premium initially increased in all three countries between 1995 and 2000, and declined subsequently. Therefore, to better examine the accuracy of our model, we re-run the experiments for shorter time horizons and determine whether the skill premium generated by the model also display the kind of non-monotonic behavior observed prior to and after 2000. To do this, we first simulate the changes in all three shocks between 1995 and 2000. Next, we construct SAMs for the three countries using the year 2000 as the base year, and simulate the changes in the shocks that occurred between 2000 and 2008. The SAMs for the year 2000 are shown in Appendix 4, and the shocks for the two sub-periods are shown in Tables 16 and 17 in Appendix 5.

Table 6: Skill Premium Patterns 1995-2000 and 2000-2008 (percent change)

\begin{tabular}{lrrrrrrr}
\hline & \multicolumn{3}{c}{$1995-2000$} & & \multicolumn{3}{c}{$2000-2008$} \\
\cline { 2 - 5 } \cline { 7 - 8 } Experiment & Estonia & Latvia & Lithuania & & Estonia & Latvia & Lithuania \\
\hline Data & 4.3 & 20.7 & 5.3 & & -24.4 & -4.4 & -18.4 \\
Joint & -18.0 & 31.3 & 3.5 & & 1.4 & -8.6 & -34.4 \\
ToT & -1.0 & -2.6 & -0.7 & & -0.5 & 0.5 & 0.5 \\
Capital deepening & 12.0 & 22.7 & 14.4 & & 26.8 & 39.5 & 23.9 \\
Skill supply & -27.1 & 10.1 & -9.5 & & -21.2 & -37.0 & -49.9 \\
\hline
\end{tabular}

As reported in Table 6, our model is able to reproduce the initial rise and subsequent fall of the skill premium observed during the two sub-periods for the Latvian and Lithuanian cases. The model generates a large increase in the skill premium for Latvia between 1995 and 2000, as both capital deepening and changes in the skill supply lead to rises in the skill premium. In fact, Latvia experienced a sizable decrease in the skilled working-age population during this period, which accounts for the rising skill premium. For the 2000-2008 period, the model yields a small decline in the skill premium, since the effects of capital deepening and changes in the skill supply offset each other. At the same time, the model generates a small increase in the Lithuanian skill premium for the first sub-period, as the effect of capital deepening slightly dominates that of skill supply changes. For the period between 2000 and 2008, changes in the skill supply play a dominant role in the model in driving down the skill premium. 
While the movements in the skill premium that our model generates are in line with those observed in the data for Latvia and Lithuania, we cannot quite capture the timing of the skill premium patterns for the Estonian case. In the data, the skill premium in Estonia increased slightly between 1995 and 2000, while our model predicts a large fall in the relative skilled wage since the labor supply effect dominates the labor demand forces. Moreover, the significant decrease in the Estonian skill premium observed after 2000 cannot be matched by our simulations. Since our model only considers the contemporaneous effects of labor supply and demand factors, we are unable to explain why the labor supply factors have this lagged effect on the skill premium in Estonia. This might be due to country-specific factors that are not explicitly included in our model. For example, as documented in Toomet (2011), there is a large fraction - almost one third - of ethnic Russians in Estonia that, although similar to the rest of the population in terms of human capital levels, significantly lags behind in terms of income growth. In the presence of such pervasive differentiation in the labor market - which our model does not contemplate - we could certainly expect large increases in the supply of skilled workers to reduce the skill premium over a longer horizon, though not immediately.

\subsection{The Role of Trade Elasticities}

We now explore whether our findings depend on the choice of the trade elasticities. Kehoe and Ruhl (2008) show that as the Armington elasticity of substitution increases, changes in the terms of trade have larger effects on real output. Our results concur with their findings, as higher elasticities of import substitution lead to reallocation of resources across sectors of larger magnitudes and, in turn, to larger changes in the skill premium. Table 7 shows the results of the numerical experiments when we re-run the simulations using alternative values for $\rho_{m}$. The values we use, 0.758, 0.844 and 0.879, are frequently cited in the literature, and are taken from Simonovska and Waugh (2014), Ruhl (2008), and Eaton and Kortum (2002), respectively (recall that our benchmark value of 0.827 is the simple average of those three values).

We find that varying the elasticity of substitution has little impact on changes in the skill premium in the joint simulation, but has more significant implications under the terms of trade experiment. The values of $\rho_{m}$ that we use imply import elasticities that range from 4.13 to 8.26 . That $100 \%$ increase in the import elasticity is associated with additional decreases in the skill premium in the ToT experiment of approximately 2 percentage points in Estonia (from -1.5\% to -3.6\%), 2.2 percentage points in Latvia (from $-1.0 \%$ to $-3.2 \%$ ), and 0.8 percentage points in Lithuania (from $-1.1 \%$ to $-1.8 \%$ ). The fact that higher import elasticities are associated with larger changes in the skill premium highlights the Heckscher- 
Ohlin mechanism, which predicts that changes in trade volumes lead to larger shifts towards the unskilled sectors, where these countries enjoy comparative advantages.

Table 7: Sensitivity Analysis: Changes in the Import Elasticity $\rho_{m}$ (percent change)

\begin{tabular}{llrrrr}
\hline & & \multicolumn{4}{c}{ Change in Skill Premium } \\
\cline { 3 - 6 } Country & Experiment & $\rho_{m}=0.758$ & $\rho_{m}=0.827$ & $\rho_{m}=0.844$ & $\rho_{m}=0.879$ \\
\hline \multirow{2}{*}{ Estonia } & Joint & -22.3 & -22.4 & -22.5 & -22.9 \\
& ToT & -1.5 & -2.2 & -2.5 & -3.6 \\
\multirow{2}{*}{ Latvia } & Joint & 10.7 & 9.8 & 9.6 & 8.8 \\
& ToT & -1.0 & -1.9 & -2.3 & -3.2 \\
\multirow{2}{*}{ Lithuania } & Joint & -35.5 & -35.3 & -35.3 & -35.2 \\
& ToT & -1.1 & -1.3 & -1.4 & -1.8 \\
\hline
\end{tabular}

Next, we run a similar robustness check for the export elasticity of substitution. We use two alternatives: one where the value of $\rho_{x}$ is equal to 0.827 (a value identical to our benchmark figure for $\rho_{m}$ ), and another where the value of $\rho_{x}$ is equal to 0.9135, which translates into an export elasticity which is twice as large as the one implied by our previous choice of $\rho_{x}=0.827$. The corresponding results are presented in Table 8 .

As in the previous case, changing $\rho_{x}$ only affects the ToT experiment results and has negligible effects on the skill premium under the joint experiment. The values of $\rho_{x}$ used in this robustness check imply elasticities that range from 5.78 to 11.56 . In the ToT experiment, the $100 \%$ increase in the export elasticity is associated with a larger decrease in the skill premium of around 0.9 percentage points in Estonia, and a smaller decline in the skill premium in Latvia. In Lithuania, meanwhile, increases in export elasticity switch the direction of the skill premium changes from increasing to decreasing. In addition, the relative magnitude of the changes in the skill premium is the largest in the Lithuanian case, at 2.8 percentage points (moving from a $0.6 \%$ increase to a $2.2 \%$ decrease).

\subsection{The Role of Capital-Skill Complementarity}

In the benchmark experiments, we used the values of $\rho$ and $\sigma$ reported in Krusell et al. (2000). Since those values implied a higher elasticity of substitution between equipment capital and unskilled labor than between equipment capital and skilled labor, capital-skill complementarity was embedded in the model. Here, we assess the robustness of our results to the assumption of capital-skill complementarity in production. We conduct our simulation with two alternative specifications: the first one, with $\rho=\sigma=0$, implies a Cobb-Douglas production function, where the elasticities between equipment capital and the two types of 
Table 8: Sensitivity Analysis: Changes in the Export Elasticity $\rho_{x}$ (percent change)

\begin{tabular}{llrrr}
\hline & & \multicolumn{3}{c}{ Change in Skill Premium } \\
\cline { 3 - 5 } Country & Experiment & $\rho_{x}=0.827$ & $\rho_{x}=0.9$ & $\rho_{x}=0.9135$ \\
\hline \multirow{2}{*}{ Estonia } & Joint & -22.7 & -22.4 & -22.4 \\
& ToT & -1.6 & -2.2 & -2.5 \\
Latvia & Joint & 9.1 & 9.8 & 10.1 \\
& ToT & -2.3 & -1.9 & -1.8 \\
\multirow{2}{*}{ Lithuania } & Joint & -35.0 & -35.3 & -35.6 \\
& ToT & 0.6 & -1.3 & -2.2 \\
\hline
\end{tabular}

labor are equal to one. In the second specification, we strengthen the degree of capital-skill complementarity by using the average of the parameter values found in Polgreen and Silos (2008) (which is in itself a sensitivity analysis of the exercise conducted in Krusell et al., 2000). The averages yield values of $\rho=-0.357$ and $\sigma=0.659$.

The results of this sensitivity analysis are depicted in Table 9, where we also present our benchmark findings. We find that the term $(\sigma-\rho)$ in equation (11) effectively gauges the degree of capital-skill complementarity and how the growth of capital equipment affects the skill premium. Under the Cobb-Douglas specification, since $\rho=\sigma$, the first term in the equation (11) cancels and the skill premium only depends on the relative growth rates of skilled and unskilled labor supply. Consequently, increases in capital equipment play no role in the evolution of the skill premium, and the absence of capital-skill complementarity results in large decreases in the skill premium under the joint experiment for all three countries. In addition, since $\sigma$ governs the elasticity of substitution between equipment capital and unskilled labor, larger values of $\sigma$ (implying larger elasticities) lead to smaller effects of relative skill supplies on the skill premium. Finally, incorporating a stronger degree of capital-skill complementarity implied by the values in Polgreen and Silos (2008), results in the joint experiment still showing diverging skill premium patterns across the Baltics, in line with our qualitative findings under the benchmark parameters.

\subsection{The Role of Preferences for Consumption, Labor and Leisure}

Our last set of sensitivity experiments focuses on the role of the preference parameters. In the benchmark simulations, the parameter $\eta$ - which determines the elasticity of substitution between the different consumption goods (including the investment good) - was set to -1 . This implied an elasticity of substitution among goods of 0.5. As shown in the first column of Table 10, changing this parameter to the value of 0 - implying a logarithmic utility function- 
Table 9: Sensitivity Analysis: Changes in the Technology Parameters (percent change)

\begin{tabular}{llrrr}
\hline & & \multicolumn{3}{c}{ Change in Skill Premium } \\
\cline { 3 - 5 } Country & Experiment & $\rho=0$ & $\rho=-0.5$ & $\rho=-0.357$ \\
\cline { 3 - 5 } Estonia & Joint & $\sigma=0$ & $\sigma=0.4$ & $\sigma=0.659$ \\
\cline { 3 - 5 } & ToT & -49.6 & -22.4 & -4.8 \\
& Capital deepening & -3.3 & -2.2 & -1.3 \\
& Skill supply & -0.8 & 27.0 & 33.2 \\
& Joint & -48.7 & -41.5 & -31.1 \\
& ToT & -34.5 & 9.8 & 37.2 \\
& Capital deepening & -2.4 & -1.9 & -1.4 \\
& Skill supply & -1.7 & 49.3 & 71.7 \\
Lithuania & Joint & -31.3 & -28.2 & -22.5 \\
& ToT & -59.4 & -35.3 & -15.4 \\
& Capital deepening & -2.1 & -1.3 & -0.7 \\
& Skill supply & -0.4 & 28.9 & 39.5 \\
& & -59.4 & -53.6 & -43.6 \\
\hline
\end{tabular}

does not lead to any noticeable differences in the changes of the skill premium from our benchmark results, for either the individual or the joint experiment.

Next, we examine the effect of varying the degree of elasticity between aggregate consumption and leisure, which is governed by the value of $\psi$. We test two alternative values for $\psi$ : one where $\psi=0$, yielding a Cobb-Douglas utility function; and another with $\psi=-1.5$, where the elasticity of substitution between consumption and leisure is 0.4 , or exactly half the value we use in the benchmark simulations. We find that, the lower the elasticity between consumption and leisure, the larger the changes in the skill premium, especially in the capital deepening and relative skill supply experiments. For example, with a $50 \%$ reduction in the elasticity, the additional increases in the skill premium under the capital deepening experiment range from 8.8 percentage points in Estonia to 18.2 percentage points in Latvia. The fact that changes in the labor-leisure margin also affect the capital deepening experiment is due to the different degrees of substitution between capital and the two types of labor. As for the relative skill supply changes, additional decreases in the skill premium range from 6.9 percentage points in Latvia, to as high as 9.8 percentage points in Lithuania.

Finally, in the last column of Table 10 we set $\zeta_{j}=1$. This is the case where leisure does not enter the utility function and labor is inelastically supplied. When the labor-leisure decision is no longer endogenously determined, the qualitative implications for the joint experiment remain unchanged. However, we note that the magnitudes of the decreases in 
the skill premium in the relative skill supply experiment are smaller than in the benchmark simulation for all three countries. As a result, in the joint experiment the magnitude of the decrease in the skill premium is smaller in Estonia and Lithuania, while the skill premium increase is larger in Latvia.

Table 10: Sensitivity Analysis: Changes in the Preferences Parameters (percent change)

\begin{tabular}{llrrrrr}
\hline & & \multicolumn{4}{c}{ Change in Skill Premium } \\
\cline { 3 - 7 } Country & Experiment & $(\eta, \psi)$ & $(\eta, \psi)$ & $(\eta, \psi)$ & $(\eta, \psi)$ \\
& & $(0,-0.25)$ & $(-1,-0.25)$ & $(-1,0)$ & $(-1,-1.5)$ & $\zeta_{j}$ \\
\cline { 3 - 6 } Estonia & Joint & -22.4 & -22.4 & -21.0 & -26.3 & -17.9 \\
& ToT & -2.2 & -2.2 & -2.2 & -2.1 & -2.5 \\
& Capital Deepening & 27.0 & 27.0 & 24.1 & 35.8 & 25.0 \\
& Skill Supply & -41.5 & -41.5 & -38.5 & -49.0 & -36.4 \\
Latvia & Joint & 10.0 & 9.8 & 9.0 & 13.1 & 22.4 \\
& ToT & -1.8 & -1.9 & -1.7 & -2.6 & -2.3 \\
& Capital Deepening & 49.3 & 49.3 & 44.2 & 67.5 & 59.2 \\
& Skill Supply & -28.2 & -28.2 & -25.7 & -35.1 & -25.3 \\
Lithuania & Joint & -35.4 & -35.3 & -32.7 & -42.8 & -24.2 \\
& ToT & -1.5 & -1.3 & -1.4 & -0.6 & -1.9 \\
& Capital Deepening & 28.9 & 28.9 & 25.3 & 40.8 & 32.8 \\
& Skill Supply & -53.6 & -53.6 & -49.5 & -63.4 & -47.4 \\
\hline
\end{tabular}

\section{Conclusion}

We propose a static general equilibrium model to account for the evolution of the skill premium. Our model incorporates forces that have a biased effect on the demand for skilled and unskilled labor: international trade, which we model in the form of changes in the terms of trade, and capital-skill complementarity, which we model as expansions in the stock of equipment capital. Unlike the large majority of recent articles in the literature, our model also incorporates factors that affect the supply of labor, which we model as changes in the relative skill composition of the labor supply caused by demographic changes.

To assess the quantitative validity of the model's predictions, we apply it to account for the patterns of the skill premium in the three Baltic states-Estonia, Latvia and Lithuania. Despite initial similarities, the skill premium in these countries evolved in diverging patterns - between 1995 and 2008, the skill premium in Latvia increased by 16\%, whereas in Estonia and Lithuania it declined by $20 \%$ and $13 \%$, respectively. 
A calibrated version of our model proves our approach of incorporating both labor supply and labor demand factors to be accurate. Indeed, the numerical experiments we conduct suggest that both forces play important roles in determining the behavior of the skill premium in the Baltics. Specifically, increases in the relative skill supply generate declines in the skill premium, whereas equipment capital deepening increases the skill premium. Moreover, changes in the terms of trade lead to the reallocation of resources toward the sectors in which the Baltic states have comparative advantages, and this in turn lowers the skill premium. Simulating all three shocks simultaneously produces changes in the skill premium that are in line with the Baltic divergence: declines in the Estonian and Lithuanian skill premium of $22 \%$ and $35 \%$ respectively, and an increase of $10 \%$ in the Latvian skill premium.

Our results display robustness to the choices of trade and preference elasticities of substitution. The sensitivity exercises also highlight the importance of the capital-skill complementarity mechanism in accounting for skill premium changes. Moreover, when we run numerical simulations of our model over shorter periods of time to account for the nonmonotonic behavior of the skill premium before and after the year 2000, we are able to capture the initial rise and subsequent fall of the skill premium in Latvia and Lithuania, although not for Estonia. We conjecture that this could be due to institutional features in the labor markets that in some instances have non-negligible effects on the skill premium. Assessing the role of such country-specific factors is beyond the scope of this article, but would suitably complement the findings of our analysis. 


\section{Appendix 1: Sectoral Aggregation and Skill Intensities in 1995}

Table 11: Sectoral Aggregation and Skill Intensities (Share of Hours by Skilled Workers) in 1995

\begin{tabular}{clrrr}
\hline \multirow{2}{*}{ Aggregation } & ISIC Rev. 3 Sectors & \multicolumn{3}{c}{ Skill Intensity (percent) } \\
\cline { 2 - 4 } & & Estonia & Latvia & Lithuania \\
\hline \multirow{3}{*}{ Goods } & Agriculture & 10.7 & 4.4 & 4.1 \\
(Unskilled) $)$ & All ming & 16.1 & 12.6 & 18.0 \\
& Average & 20.6 & 13.2 & 15.6 \\
\hline \multirow{5}{*}{ Services } & Electricity and gas service & 15.8 & 10.1 & 12.6 \\
\cline { 2 - 4 } (Skilled) & Construction & 18.4 & 16.0 & 15.7 \\
& Wholesale and retail service & 24.3 & 21.4 & 17.8 \\
& Hotel and restaurants & 41.5 & 26.3 & 34.7 \\
& Real estate and business service & 27.9 & 10.3 & 33.8 \\
& Public service & 34.7 & 25.6 & 28.1 \\
& Education & 67.0 & 56.7 & 52.9 \\
& Health & 42.1 & 32.4 & 53.5 \\
& Social and personal service & 41.9 & 63.9 & 70.0 \\
& Average & 55.7 & 34.0 & 42.7 \\
& & 42.7 & 20.0 & 29.5 \\
& & & 32.0 & 38.6 \\
\hline
\end{tabular}



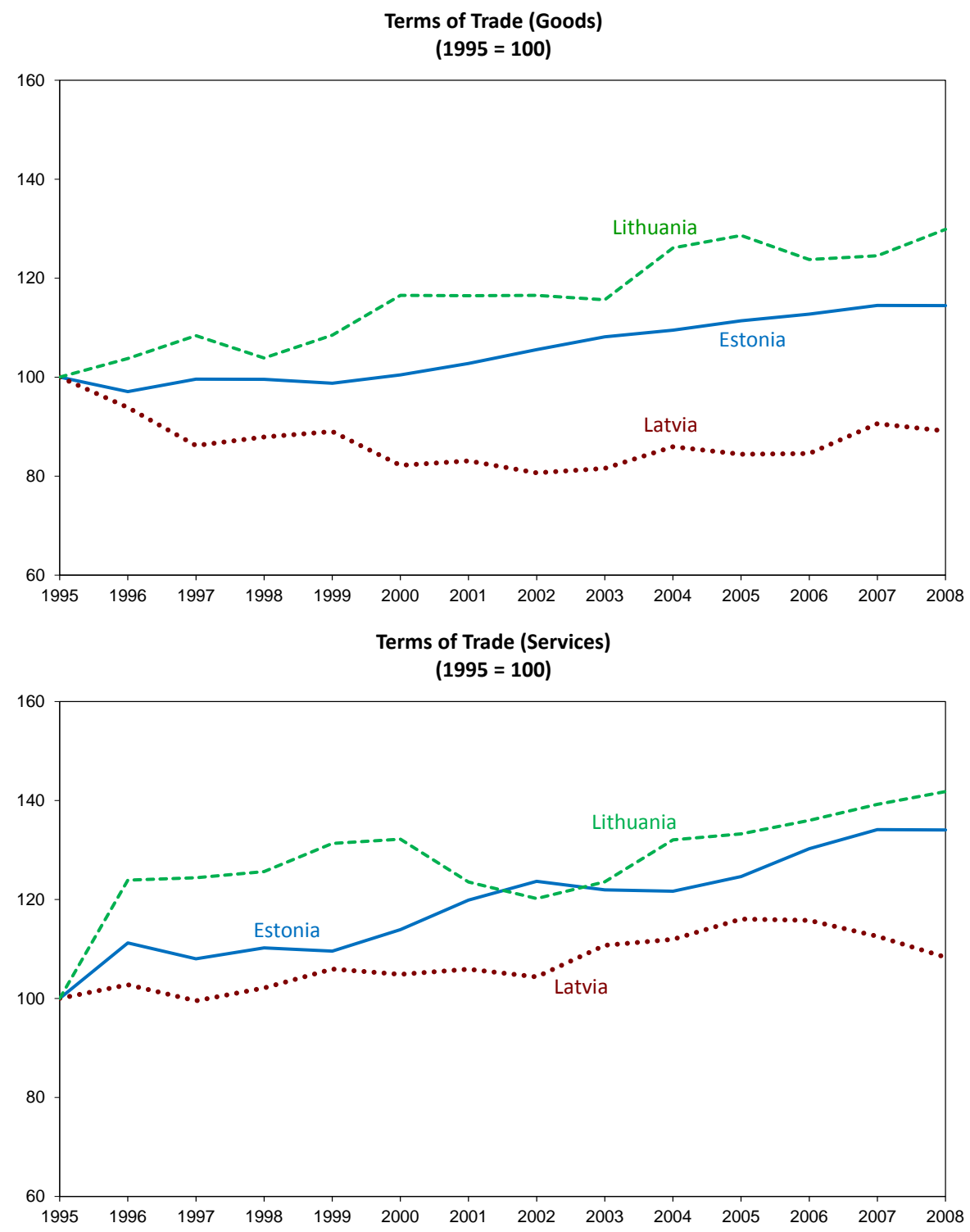

Figure 5: Terms of trade for goods (top) and services (bottom) in the Baltic states, $1995=100$ 


\section{Appendix 2: Social Accounting Matrices (1995)}
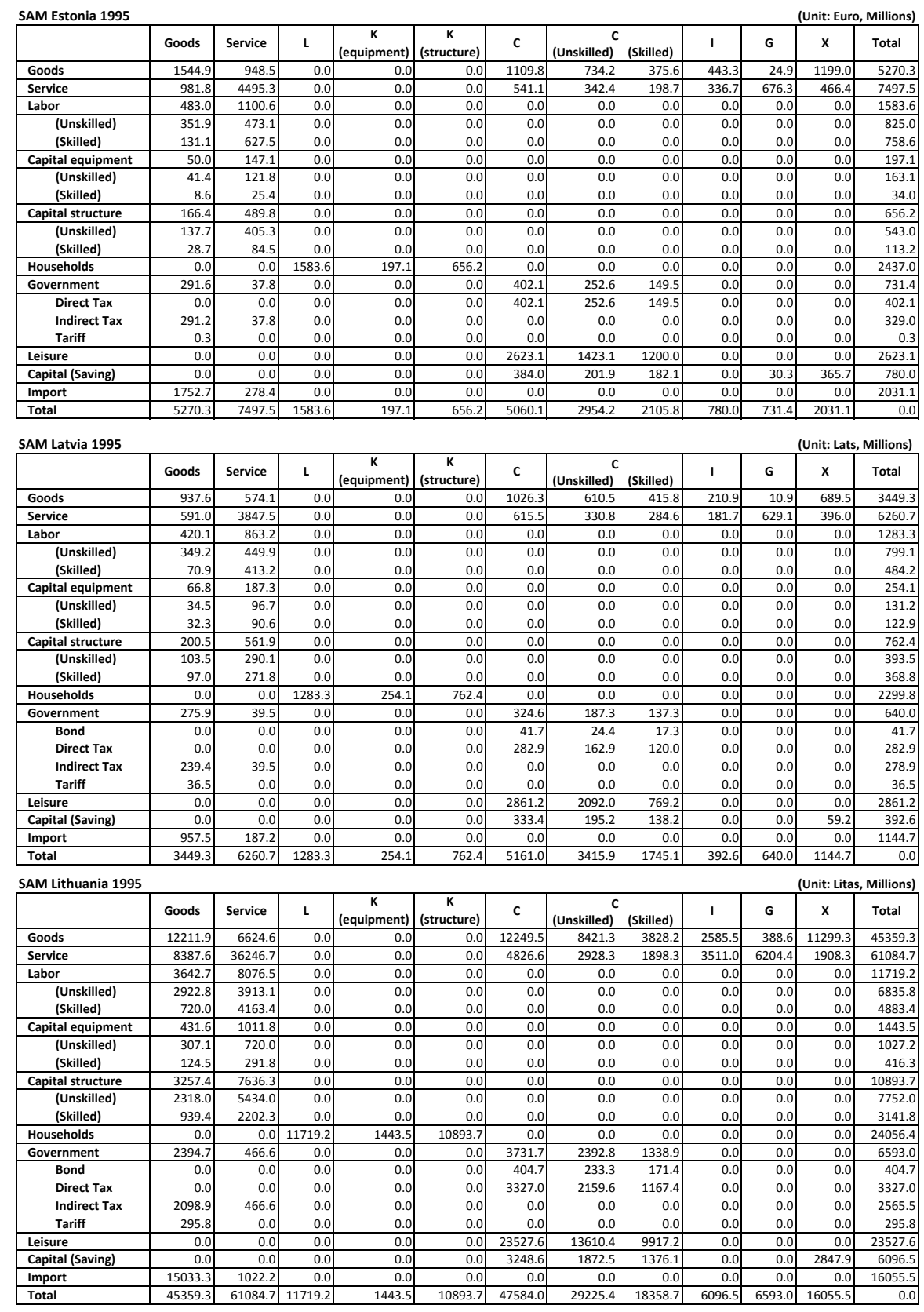

Figure 6: Estonia (top), Latvia (middle) and Lithuania (bottom) Social Accounting Matrices, 1995 


\section{Appendix 3: Calibrated Parameters (1995)}

Table 12: Preferences Parameters: Skilled $\left(\theta^{s}\right)$, Unskilled $\left(\theta^{u}\right)$ and Government $\left(\theta^{g}\right)$

\begin{tabular}{|c|c|c|c|c|c|c|c|c|c|}
\hline & \multicolumn{3}{|c|}{ Estonia } & \multicolumn{3}{|c|}{ Latvia } & \multicolumn{3}{|c|}{ Lithuania } \\
\hline & $\theta^{s}$ & $\theta^{u}$ & $\theta^{g}$ & $\theta^{s}$ & $\theta^{u}$ & $\theta^{g}$ & $\theta^{s}$ & $\theta^{u}$ & $\theta^{g}$ \\
\hline$c_{G}$ & 0.660 & 0.773 & 0.034 & 0.633 & 0.716 & 0.017 & 0.726 & 0.854 & 0.059 \\
\hline$c_{S}$ & 0.185 & 0.168 & 0.925 & 0.297 & 0.210 & 0.983 & 0.179 & 0.103 & 0.941 \\
\hline$c_{i n v}$ & 0.155 & 0.059 & 0.041 & 0.070 & 0.073 & & 0.094 & 0.042 & \\
\hline$c_{b}$ & & & & 0.001 & 0.001 & & 0.001 & 0.001 & \\
\hline $1-\zeta$ & 0.695 & 0.596 & & 0.528 & 0.726 & & 0.652 & 0.552 & \\
\hline
\end{tabular}

Table 13: Domestic Goods Firm Parameters

\begin{tabular}{|c|c|c|c|c|c|c|c|c|c|c|c|c|}
\hline & \multicolumn{4}{|c|}{ Estonia } & \multicolumn{4}{|c|}{ Latvia } & \multicolumn{4}{|c|}{ Lithuania } \\
\hline & $\alpha$ & $\beta$ & $\mu$ & $\lambda$ & $\alpha$ & $\beta$ & $\mu$ & $\lambda$ & $\alpha$ & $\beta$ & $\mu$ & $\lambda$ \\
\hline & 238 & 17 & 0.1 & 0.455 & 292 & 12.422 & 0 . & 0 & 0.444 & 13.330 & 0 & 0.4 \\
\hline$d$, & .282 & 14.608 & 0.102 & 0.614 & 0.349 & 14.010 & 0.234 & 0.601 & 0.457 & 11.844 & 0.107 & 0.584 \\
\hline
\end{tabular}

Table 14: Final Goods Firm Parameters

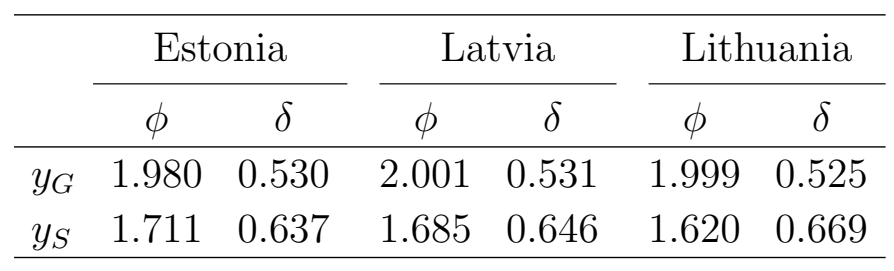




\section{Appendix 4: Social Accounting Matrices (2000)}

\begin{tabular}{|c|c|c|c|c|c|c|c|c|c|c|c|c|}
\hline \multirow[t]{2}{*}{ SAM Estonia 2000} & \multirow[b]{2}{*}{ Goods } & \multirow[b]{2}{*}{ Service } & \multirow[b]{2}{*}{ L } & \multirow[b]{2}{*}{\begin{tabular}{|c|}
$\mathrm{K}$ \\
(equipment)
\end{tabular}} & \multirow[b]{2}{*}{\begin{tabular}{|c|}
$\mathrm{K}$ \\
(structure)
\end{tabular}} & \multirow[b]{2}{*}{ C } & \multirow[b]{2}{*}{\begin{tabular}{|r} 
C \\
(Unskilled)
\end{tabular}} & \multirow[b]{2}{*}{ (Skilled) } & \multirow[b]{2}{*}{1} & \multicolumn{3}{|c|}{ (Unit: Euro, Millions) } \\
\hline & & & & & & & & & & G & $\mathrm{x}$ & Total \\
\hline Goods & 3323.0 & $\begin{array}{l}1921.0 \\
\end{array}$ & 0.0 & 0.0 & 0.0 & 2134.3 & 1412.0 & 722.3 & 941.5 & 39.3 & 3619.0 & 11978.1 \\
\hline Service & 2149.5 & 11290.4 & 0.0 & 0.0 & 0.0 & 1626.4 & 1029.1 & 597.3 & 807.2 & $\begin{array}{ll}1177.5 \\
\end{array}$ & 1067.7 & 18118.7 \\
\hline Labor & 815.6 & 2292.0 & 0.0 & 0.0 & 0.0 & 0.0 & 0.0 & 0.0 & 0.0 & 0.0 & 0.0 & 3107.6 \\
\hline (Unskilled) & 584.5 & \begin{tabular}{|c|}
1118.3 \\
\end{tabular} & 0.0 & 0.0 & 0.0 & 0.0 & 0.0 & 0.0 & 0.0 & 0.0 & 0.0 & 1702.8 \\
\hline (Skilled) & 231.1 & 1173.8 & 0.0 & 0.0 & 0.0 & 0.0 & 0.0 & 0.0 & 0.0 & 0.0 & 0.0 & 1404.9 \\
\hline Capital equipment & \begin{tabular}{l|l|}
132.8 \\
\end{tabular} & 522.5 & 0.0 & 0.0 & 0.0 & 0.0 & 0.0 & 0.0 & 0.0 & 0.0 & 0.0 & 655.3 \\
\hline (Unskilled) & 97.3 & 382.7 & 0.0 & 0.0 & 0.0 & 0.0 & 0.0 & 0.0 & 0.0 & 0.0 & 0.0 & 479.9 \\
\hline (Skilled) & 35.5 & 139.8 & 0.0 & 0.0 & 0.0 & 0.0 & 0.0 & 0.0 & 0.0 & 0.0 & 0.0 & 175.4 \\
\hline $\begin{array}{l}\text { Capital structure } \\
\end{array}$ & 353.1 & 1389.0 & 0.0 & 0.0 & 0.0 & 0.0 & 0.0 & 0.0 & 0.0 & 0.0 & 0.0 & 1742.1 \\
\hline (Unskilled) & \begin{tabular}{ll|}
258.6 \\
\end{tabular} & \begin{tabular}{ll|}
1017.3 \\
\end{tabular} & 0.0 & 0.0 & 0.0 & 0.0 & 0.0 & 0.0 & 0.0 & 0.0 & 0.0 & 1275.9 \\
\hline (Skilled) & 94.5 & 371.7 & 0.0 & 0.0 & 0.0 & 0.0 & 0.0 & 0.0 & 0.0 & 0.0 & 0.0 & 466.2 \\
\hline Households & 0.0 & 0.0 & 3107.6 & 655.3 & 1742.1 & 0.0 & 0.0 & 0.0 & 0.0 & 0.0 & 0.0 & 5505.0 \\
\hline Government & 567.0 & 87.8 & 0.0 & 0.0 & 0.0 & 561.9 & 352.2 & 209.7 & 0.0 & 0.0 & 0.0 & 1216.7 \\
\hline Bond & 0.0 & 0.0 & 0.0 & 0.0 & 0.0 & 12.3 & 6.9 & 5.4 & 0.0 & 0.0 & 0.0 & 12.3 \\
\hline Direct Tax & 0.0 & 0.0 & 0.0 & 0.0 & 0.0 & 549.6 & 345.2 & 204.3 & 0.0 & 0.0 & 0.0 & 549.6 \\
\hline Indirect Tax & 522.8 & 87.8 & 0.0 & 0.0 & 0.0 & 0.0 & 0.0 & 0.0 & 0.0 & 0.0 & 0.0 & 610.7 \\
\hline Tariff & 44.2 & 0.0 & 0.0 & 0.0 & 0.0 & 0.0 & 0.0 & 0.0 & 0.0 & 0.0 & 0.0 & 44.2 \\
\hline Leisure & 0.0 & 0.0 & 0.0 & 0.0 & 0.0 & 5599.1 & 2480.6 & 3118.5 & 0.0 & 0.0 & 0.0 & 5599.1 \\
\hline Capital (Saving) & 0.0 & 0.0 & 0.0 & 0.0 & 0.0 & 1182.4 & 665.3 & $\begin{array}{l}517.0 \\
\end{array}$ & 0.0 & 0.0 & 566.3 & 1748.7 \\
\hline Import & $\begin{array}{l}4637.1 \\
\end{array}$ & 616.0 & 0.0 & 0.0 & 0.0 & 0.0 & 0.0 & 0.0 & 0.0 & 0.0 & 0.0 & 5253.1 \\
\hline Total & 11978.1 & 18118.7 & 3107.6 & 655.3 & 1742.1 & 11104.1 & 5939.2 & 5164.9 & 1748.7 & \begin{tabular}{|l|}
1216.7 \\
\end{tabular} & 5253.1 & 0.0 \\
\hline
\end{tabular}
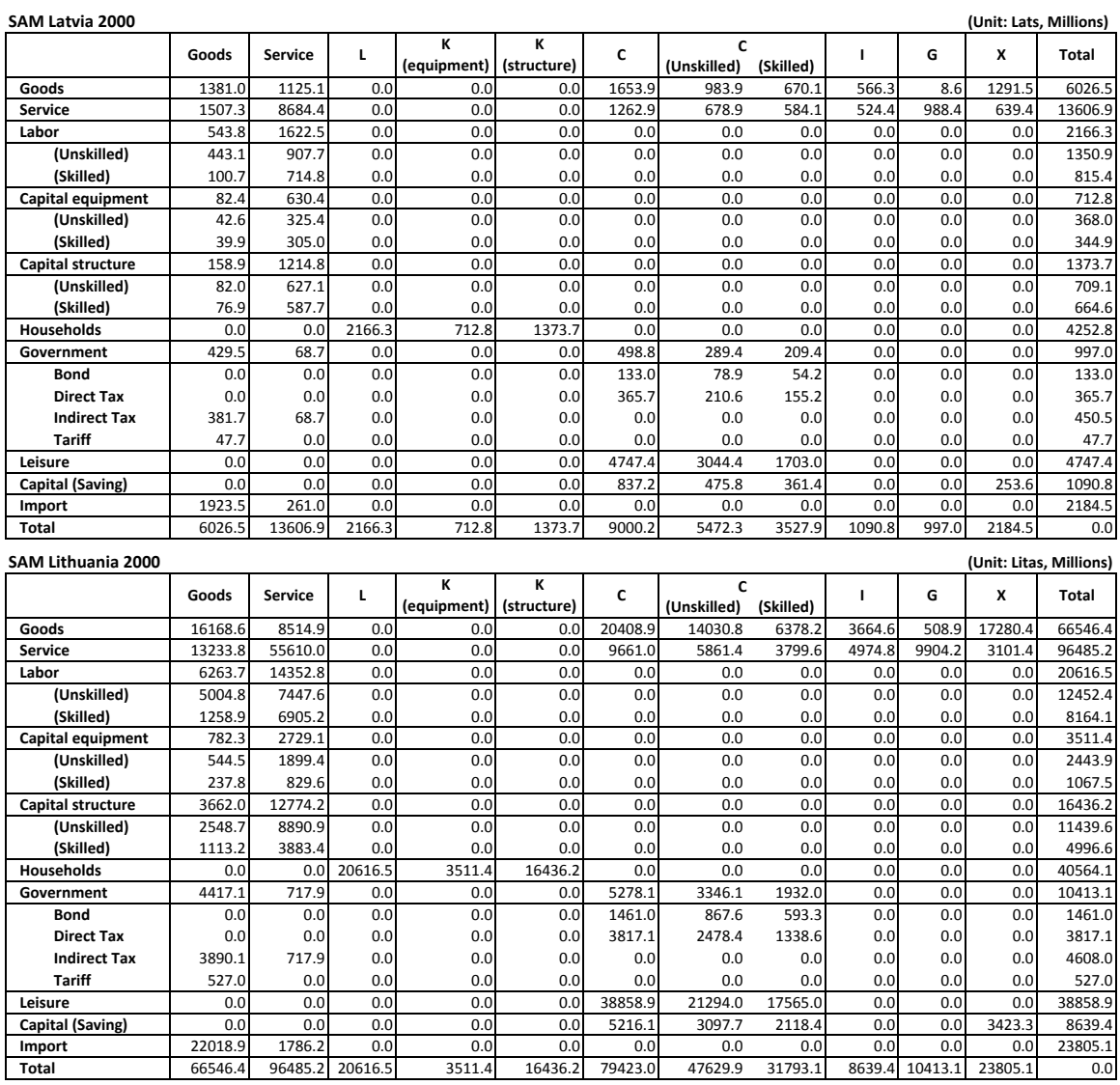

Figure 7: Estonia (top), Latvia (middle) and Lithuania (bottom) Social Accounting Matrices, 2000 


\section{Appendix 5: Exogenous Shocks for Numerical Experiments}

Table 15: Numerical Experiments - Benchmark: 1995-2008 (percent change)

\begin{tabular}{llrrr}
\hline Experiment & & Estonia & Latvia & Lithuania \\
\hline ToT & Goods & 14.5 & -10.9 & 29.9 \\
& Services & 34.0 & 8.3 & 41.8 \\
Capital deepening & Equipment & 431.0 & 774.5 & 620.5 \\
& Structures & 254.3 & 387.7 & 184.0 \\
\multirow{3}{*}{ Skill supply } & Skilled & 53.0 & 31.0 & 91.1 \\
& Unskilled & -15.3 & -5.8 & -12.7 \\
\hline
\end{tabular}

Table 16: Numerical Experiments - Sensitivity Analysis: 1995-2000 (percent change)

\begin{tabular}{llrrr}
\hline Experiment & & Estonia & Latvia & Lithuania \\
\hline ToT & Goods & 0.5 & -17.8 & 16.5 \\
& Services & 13.9 & 4.9 & 32.2 \\
Capital deepening & Equipment & 92.7 & 159.3 & 143.1 \\
& Structures & 54.1 & 66.5 & 50.8 \\
\multirow{3}{*}{ Skill supply } & Skilled & 27.9 & -9.1 & 8.2 \\
& Unskilled & -9.6 & -0.5 & -2.7 \\
\hline
\end{tabular}

Table 17: Numerical Experiments - Sensitivity Analysis: 2000-2008 (percent change)

\begin{tabular}{llrrr}
\hline Experiment & & Estonia & Latvia & Lithuania \\
\hline ToT & Goods & 14.0 & 8.5 & 11.4 \\
& Services & 17.7 & 3.3 & 7.3 \\
Capital deepening & Equipment & 175.5 & 237.3 & 196.4 \\
& Structures & 129.9 & 192.9 & 88.3 \\
\multirow{3}{*}{ Skill supply } & Skilled & 19.6 & 44.2 & 76.5 \\
& Unskilled & -6.3 & -5.3 & -10.2 \\
\hline
\end{tabular}

\section{References}

Auerbach, A., Kotlikoff, L.: Dynamic Fiscal Policy. Cambridge University Press, Cambridge (1987)

Barro, R. J., Lee, J. W.: A new data set of educational attainment in the world, 1950-2010, J. Dev. Econ. 104(C), 184-198 (2013) 
Bems, R., Jönsson Hartelius, K.: Trade deficits in the Baltic states: how long will the party last? Rev. Econ. Dyn. 9, 179-209 (2006)

Caselli, F.: Accounting for cross-country income differences. In: Aghion, P., Durlauf, S. (eds.) Handbook of Economic Growth, pp. 679-741. North Holland, Amsterdam (2005)

Eaton, J., Kortum, S.: Technology, geography and trade. Econometrica 70, 1741-1779 (2002)

Ghez, G., Becker, G.: The Allocation of Time and Goods over the Life Cycle. Columbia University Press, New York (1975)

Goldin, C., Katz, L.: The Race Between Education and Technology. The Belknap Press of Harvard University Press, Cambridge (2008)

Griliches, Z.: Capital-skill complementarity. Rev. Econ. Stat. 51, 465-468 (1969)

Hall, R. E., Jones, C. I.: Why do some countries produce so much more output per worker than others? Q.J. Econ. 114, 83-116 (1999)

Katz, L. F., Murphy, K. M.: Changes in relative wages, 1963-1987: supply and demand factors. Q.J. Econ. 107, 35-78 (1992)

Kehoe, T. J., Serra-Puche, J.: A computational general equilibrium model with endogenous unemployment: an analysis of the 1980 fiscal reform in Mexico. J. Public Econ. 22, 1-26 (1983)

Kehoe, T.J.: Social accounting matrices and applied general equilibrium models. Federal Reserve Bank of Minneapolis working paper 563 (1996)

Kehoe, T. J., Ruhl, K. J.: Are shocks to the terms of trade shocks to productivity? Rev. Econ. Dyn. 11, 804-819 (2008)

Krusell, P., Ohanian, L., Ríos-Rull, J.V., Violante, G. Capital-skill complementarity and inequality: a macroeconomic analysis. Econometrica 68, 1029-1053 (2000)

Kurokawa, Yoshinori, 2012. A survey of trade and wage inequality: anomalies, resolutions and new trends. J. Econ. Surv. 28, 169-193 (2012)

Parro, F.: Capital-skill complementarity and the skill premium in a quantitative model of trade. Am. Econ. J. Macroecon. 5, 72-117 (2013)

Polgreen, L., Silos, P.: Capital-skill complementarity and inequality: a sensitivity analysis. Rev. Econ. Dyn. 11, 302-313 (2008) 
Ripoll, M.: Trade liberalization and the skill premium in developing economies. J. Monet. Econ. 52, 601-619 (2005)

Ruhl, K. J.: The International Elasticity Puzzle. Unpublished manuscript, University of Texas at Austin (2008)

Simonovska, I., Waugh, M.: The elasticity of trade: estimates and evidence. J. of Int. Econ. 92, 34-50 (2014)

Stockman, A. C., Tesar, L. L.: Tastes and technology in a two-country model of the business cycle: explaining international comovements. Am. Econ. Rev. 85, 168-185 (1995)

Toomet, O.: Learn English, not the local language! Ethnic Russians in the Baltic states. Am. Econ. Rev. 101, 526-531 (2011)

Whalley, J.: An evaluation of the Tokyo Round Table Agreement using general equilibrium computational methods. J. Pol. Modeling 4, 341-361 (1982) 